
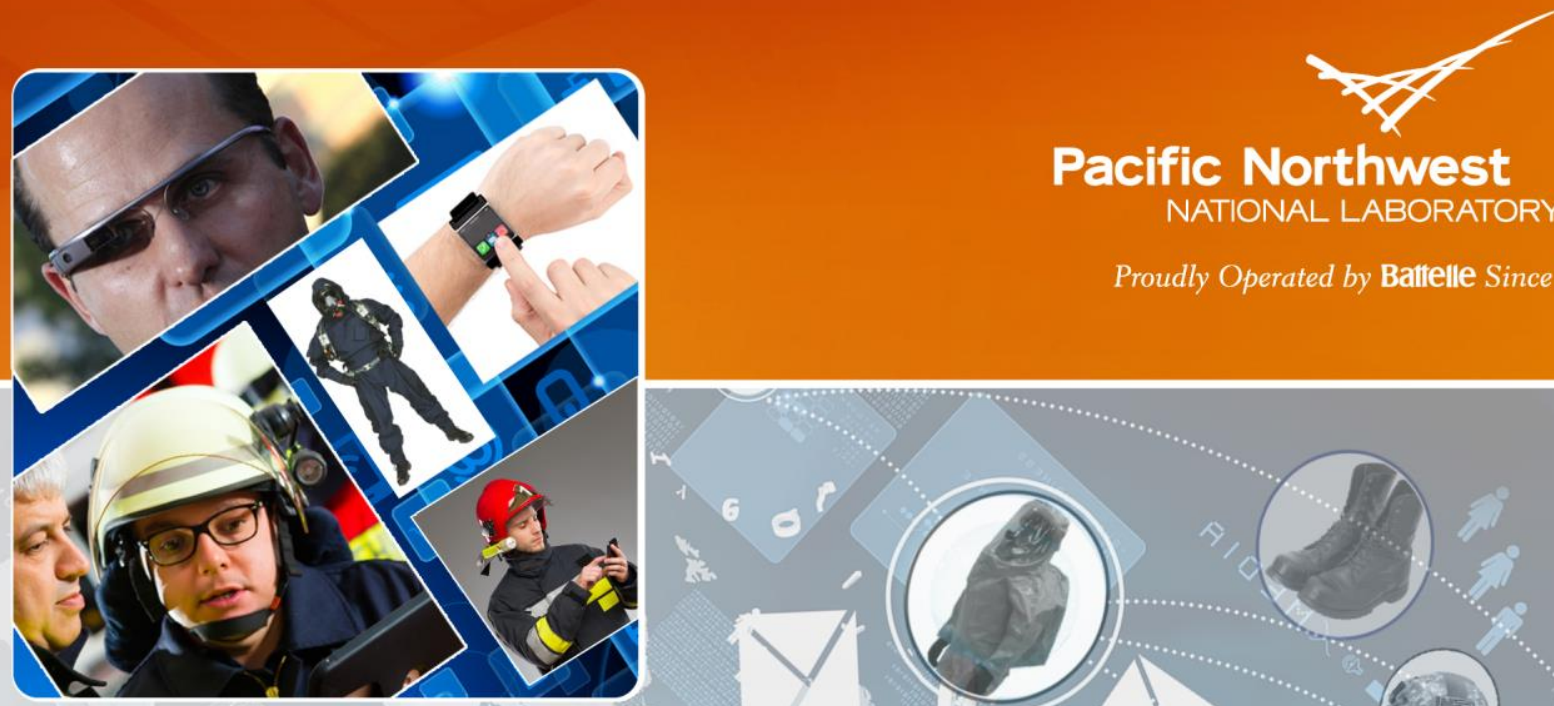

Pacific Northwest

NATIONAL LABORATORY

Proudly Operated by Battelle Since 1965

Responder Technology
Alert Monthly (December 2014)

February 2015

JF Upton

SL Stein
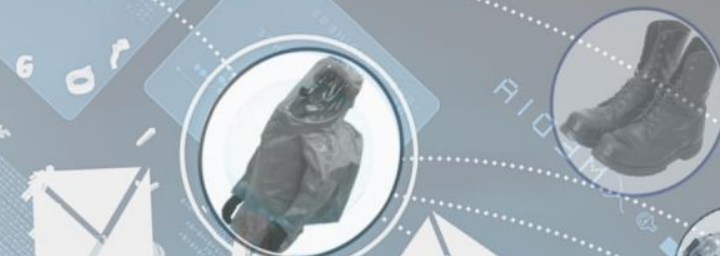

$\lim _{\rightarrow}$

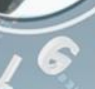




\title{
DISCLAIMER
}

This report was prepared as an account of work sponsored by an agency of the United States Government. Neither the United States Government nor any agency thereof, nor Battelle Memorial Institute, nor any of their employees, makes any warranty, express or implied, or assumes any legal liability or responsibility for the accuracy, completeness, or usefulness of any information, apparatus, product, or process disclosed, or represents that its use would not infringe privately owned rights. Reference herein to any specific commercial product, process, or service by trade name, trademark, manufacturer, or otherwise does not necessarily constitute or imply its endorsement, recommendation, or favoring by the United States Government or any agency thereof, or Battelle Memorial Institute. The views and opinions of authors expressed herein do not necessarily state or reflect those of the United States Government or any agency thereof.

\author{
PACIFIC NORTHWEST NATIONAL LABORATORY \\ operated by \\ BATTELLE \\ for the \\ UNITED STATES DEPARTMENT OF ENERGY \\ under Contract DE-AC05-76RL01830
}

Printed in the United States of America
Available to DOE and DOE contractors from the Office of Scientific and Technical Information, P.O. Box 62, Oak Ridge, TN 37831-0062; ph: (865) 576-8401 fax: $(865) 576-5728$
email: reports $a$ adonis.osti.gov
Available to the public from the National Technical Information Service 5301 Shawnee Rd., Alexandria, VA 22312 ph: (800) 553-NTIS (6847) email: orders@ntis.gov <http://www.ntis.gov/about/form.aspx> Online ordering: http://www.ntis.gov




\section{Responder Technology Alert Monthly (December 2014)}

JF Upton

SL Stein

February 2015

Prepared for the Department of Homeland Security Science and Technology Directorate under Contract HSHQPM-14-X-00058.

Pacific Northwest National Laboratory Richland, Washington 99352 

PNNL RTA Monthly Report - December 2014

\section{Acronyms and Abbreviations}

GPS

NFC

PNNL

RFID

RTA

SLAM global positioning system

near-field communications

Pacific Northwest National Laboratory

radiofrequency identification

Responder Technology Alliance

Simultaneous Localization And Mapping 



\section{Contents}

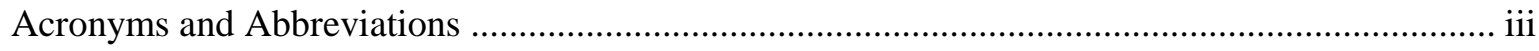

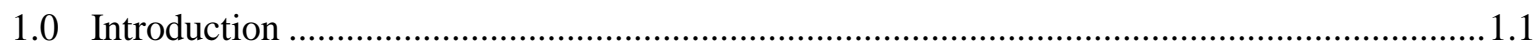

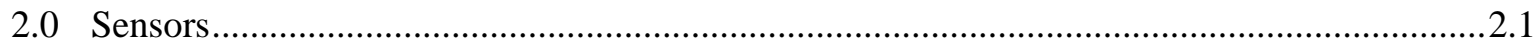

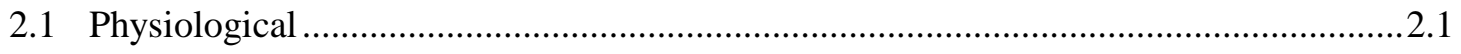

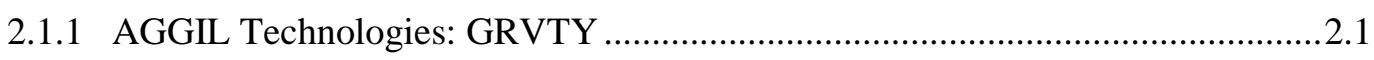

2.1.2 Biocompatible Adhesive Gel Patch............................................................... 2.1

2.1.3 Bioserenity: Wearable Epilepsy Monitoring Unit .............................................2.2

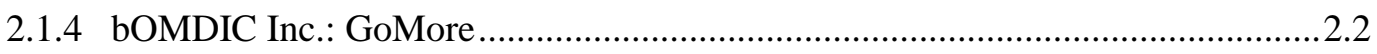

2.1.5 Cambridge Consultants: XelfieX …….......................................................2.2

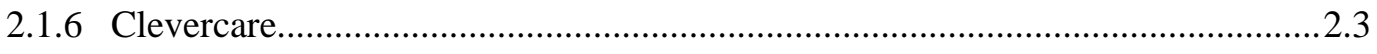

2.1.7 Globe: Wearable Advanced Sensor Platform ${ }^{\mathrm{TM}}$................................................... 2.3

2.1.8 Intel, Michael J. Fox Foundation for Parkinson's Research ..................................2.4

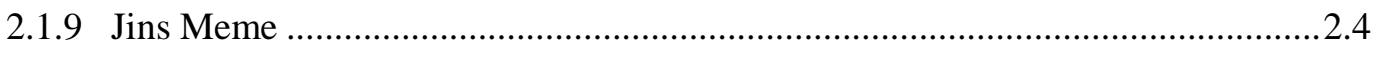

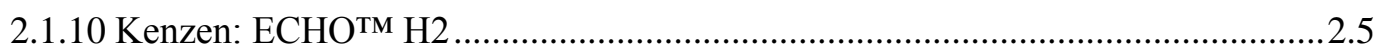

2.1.11 Li Cheng-Yuan, and You Chuang-Wen, National Taiwan University

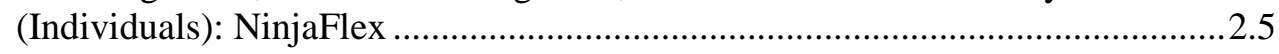

2.1.12 LifeWatch, Vital Connect: Vital Signs Patch...................................................... 2.6

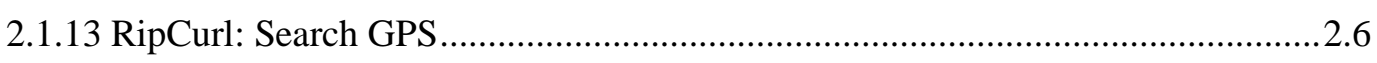

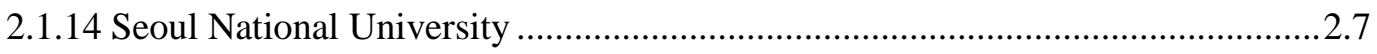

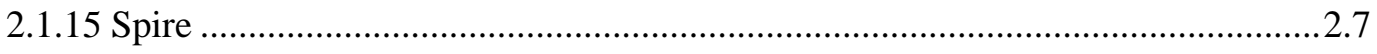

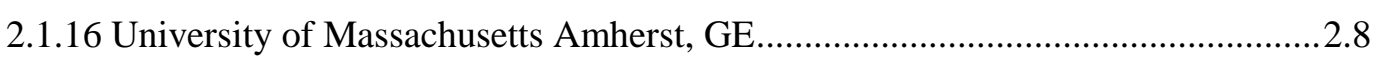

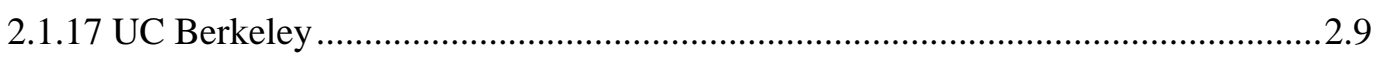

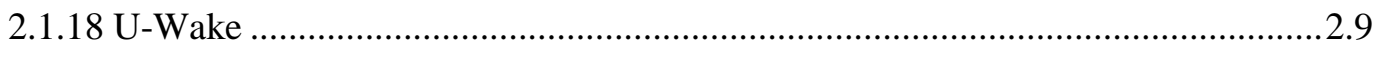

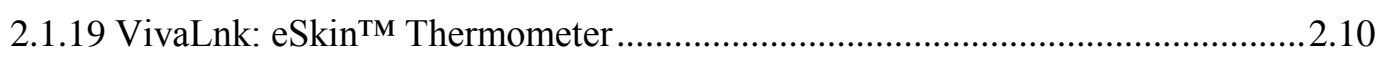

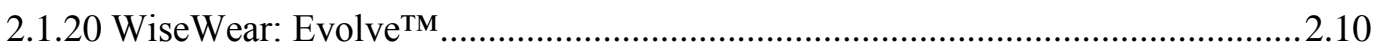

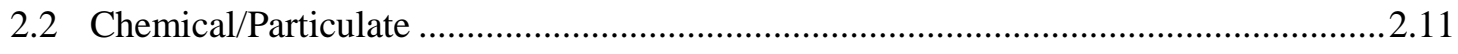

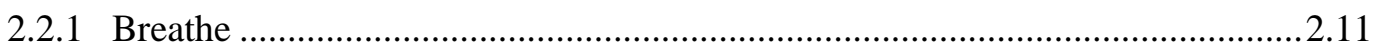

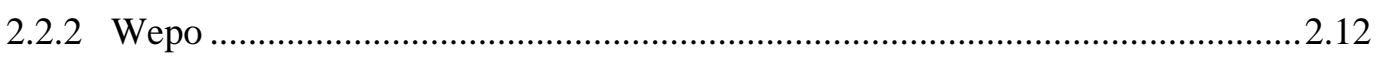

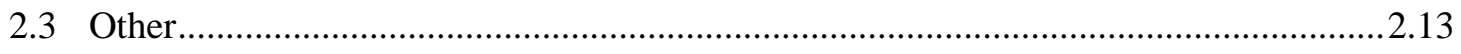

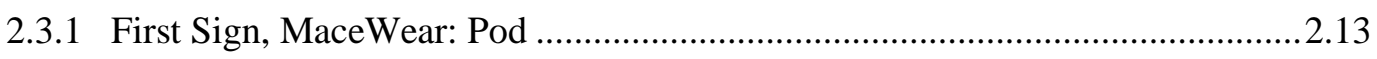

2.3.2 Pauline van Dongen and TU Eindhoven \& Textile Museum: Vigour ................2.13

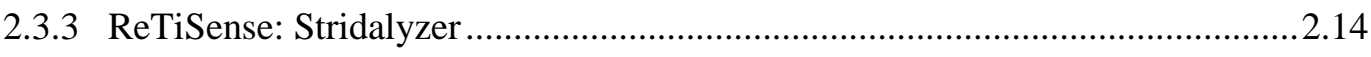

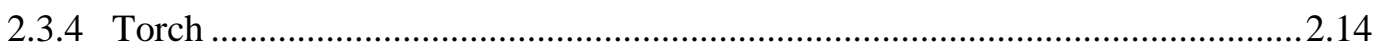

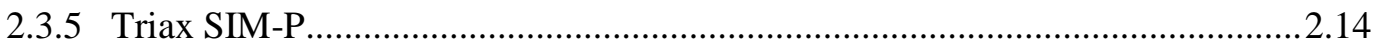

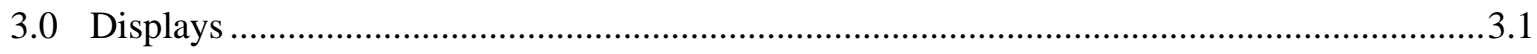

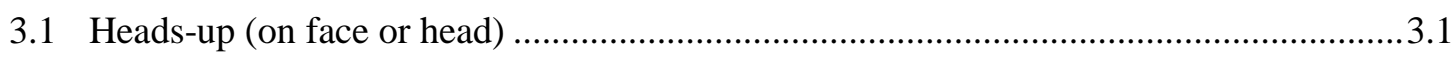

3.1.1 Intel, Luxottica Group .............................................................................. 3.1 


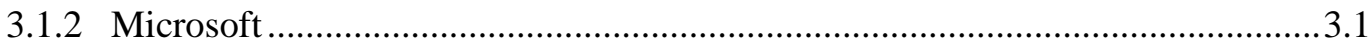

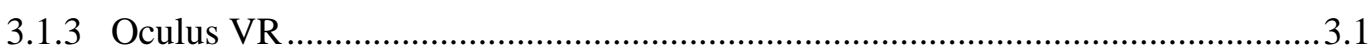

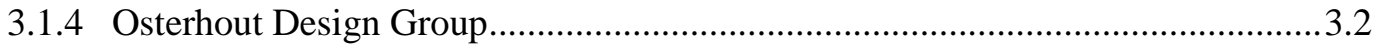

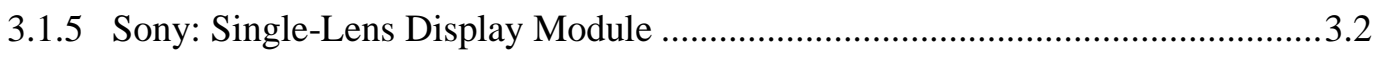

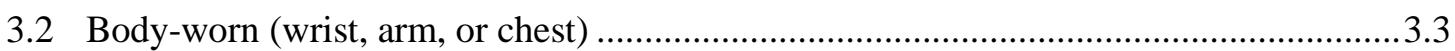

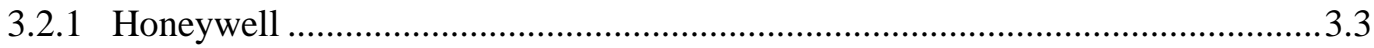

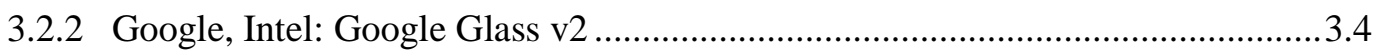

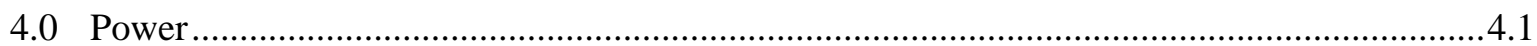

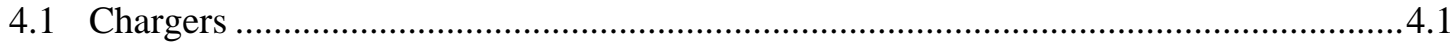

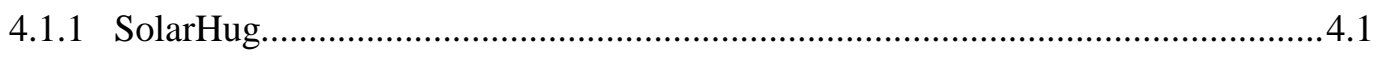

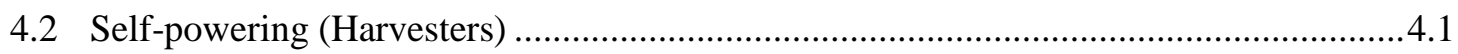

4.2.1 Lanzhou University, Chinese Academy of Sciences......................................... 4.1

4.2.2 Natick Soldier Research, Development, and Engineering Center ........................4.2

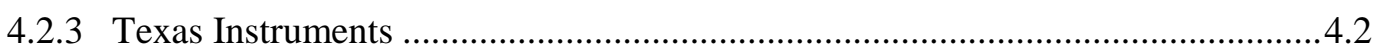

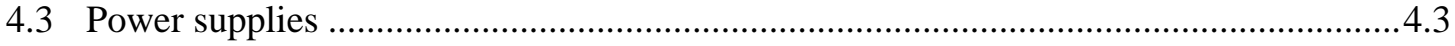

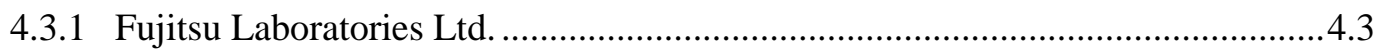

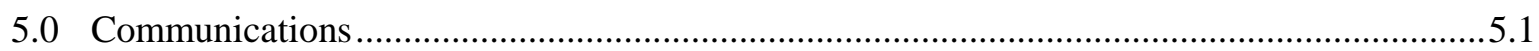

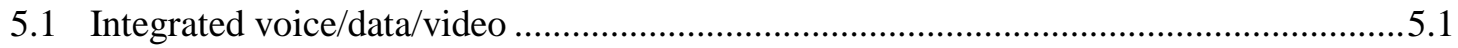

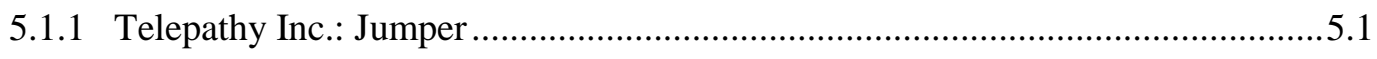

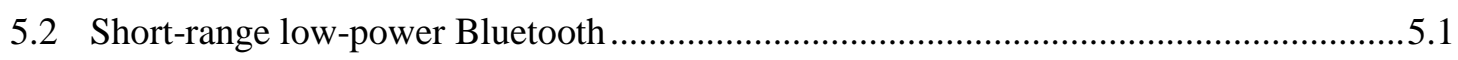

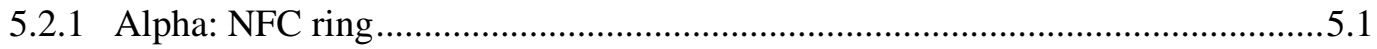

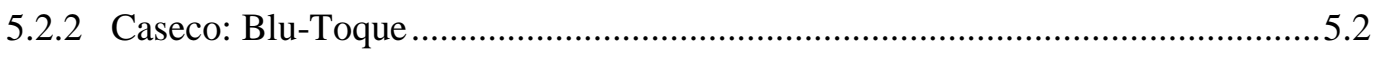

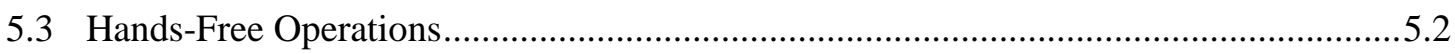

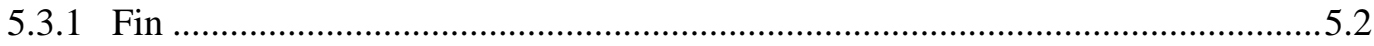

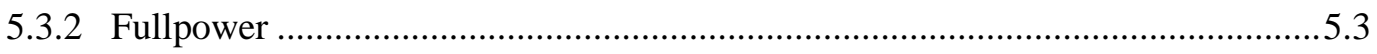

5.3.3 Institute for Integrative Nanosciences, Institute for Solid State and Materials

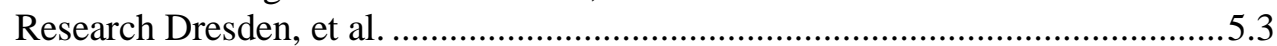

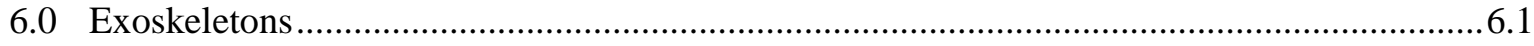

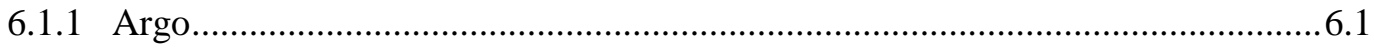

6.1.2 Daewoo Shipbuilding and Marine Engineering ............................................... 6.1

6.1.3 Defense Advanced Research Projects Agency (DARPA): Airlegs ......................6.2

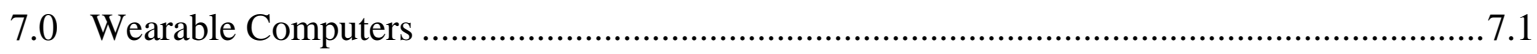

7.1.1 UK Home Office ……..........................................................................

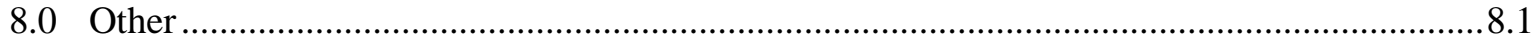

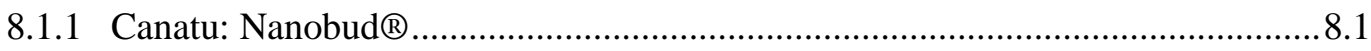

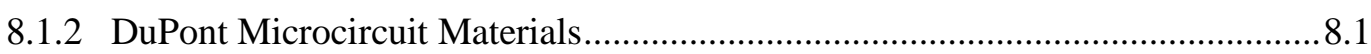

8.1.3 Elliott Fight Dynamics: StrikeTec .................................................................. 8.2

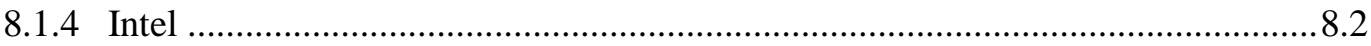


8.1.5 Massachusetts Institute of Technology: Simultaneous Localization And

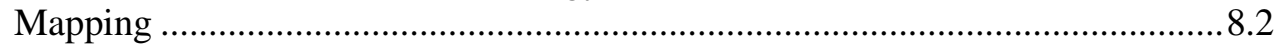

8.1.6 Massachusetts Institute of Technology, Stratasys .................................................. 8.3

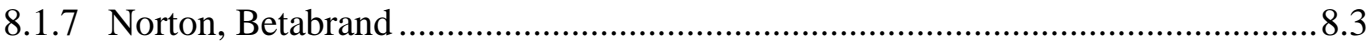

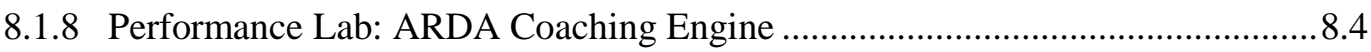

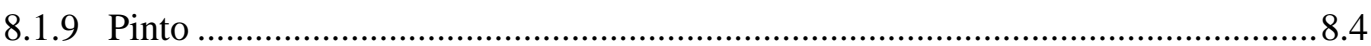

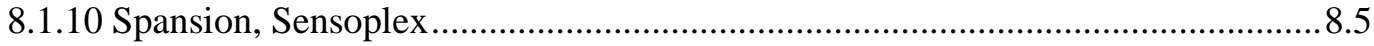

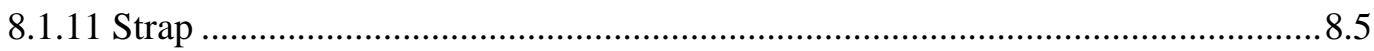

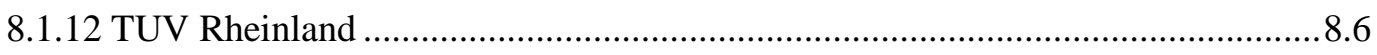

8.1.13 University of Toronto Mississauga ……............................................................ 8.6

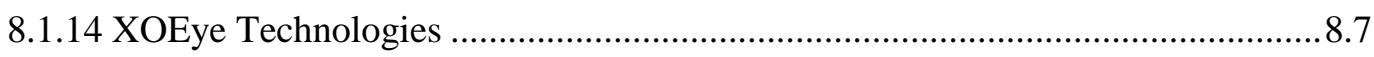

8.1.15 YESJ EXPERT, AYEIM: AYEFI................................................................... 8.7

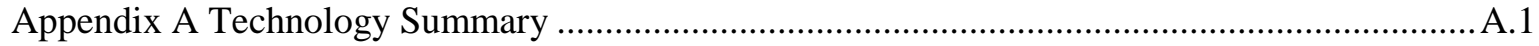



PNNL RTA Monthly Report - December 2014

\subsection{Introduction}

The Pacific Northwest National Laboratory (PNNL) is supporting the Department of Homeland Security (DHS) to advance technologies to enhance responder health and address complex and changing threat environments. The DHS Science and Technologies First Responders Group established the Responder Technology Alliance (RTA) to accelerate the development of solutions to first responder needs and requirements by identifying, analyzing, and recommending solutions that improve responder safety, enhance their ability to save lives, and minimize property loss. The end goal is for RTA to develop and implement strategies that will make effective solutions available to first responders.

As part of technology foraging for the RTA, this report summarizes technologies that are relevant in the area of "wearables," with the potential for use by first responders. The content was collected over the previous month(s) and reproduced from a general Internet search using the term wearables. Additional information is available at the websites provided. The content is organized by technology function including:

- Sensors - Devices that detect physiological, particle, and chemical activity

- Displays - Heads-up and body-worn visual displays

- Power - Wearable power systems including chargers, batteries, self-powering or harvesting technologies, and power supplies

- Integrated Communications - Voice and data communications systems utilizing Bluetooth, wireless, hands-free, ergonomically optimized systems, noise-filtering digital speakers or microphones, etc.

- Exoskeletons - Whole or partial body suit that enhances mobility and physical performance

- Wearable Computers - Body-worn data processing devices

- General - Miscellaneous technologies as well as emerging trends or recent advances in the field of wearables.

This report is not meant to be an exhaustive list nor an endorsement of any technology described herein. Rather, it is meant to provide useful information about current developments in the areas wearable technology.

A spreadsheet summarizing these technologies is available in Appendix A. For an electronic copy, contact Jaki Upton at jaki.upton@pnnl.gov. 

PNNL RTA Monthly Report - December 2014

Sensors

\subsection{Sensors}

\subsection{Physiological}

\subsubsection{AGGIL Technologies: GRVTY}

Technology name: GRVTY smart fitness band

Description: GRVTY detects changes in a user's motion and body position and uses algorithms to analyze whether the user is accidentally falling, and if so, GRVTY sends an alert to smart devices. The device is reported to detect dangerous motion patterns, texting while driving, weaving, etc. and in the case of a crash the device alerts the user's emergency contacts.

Status: Evolving

Funding: Crowdfunding

Product link: https://www.indiegogo.com/projects/grvty-wearable-detecting-fall-crash-text-driving

Source: GRVTY: Wearable detecting fall, crash \& text driving.

https://www.indiegogo.com/projects/grvty-wearable-detecting-fall-crash-text-driving

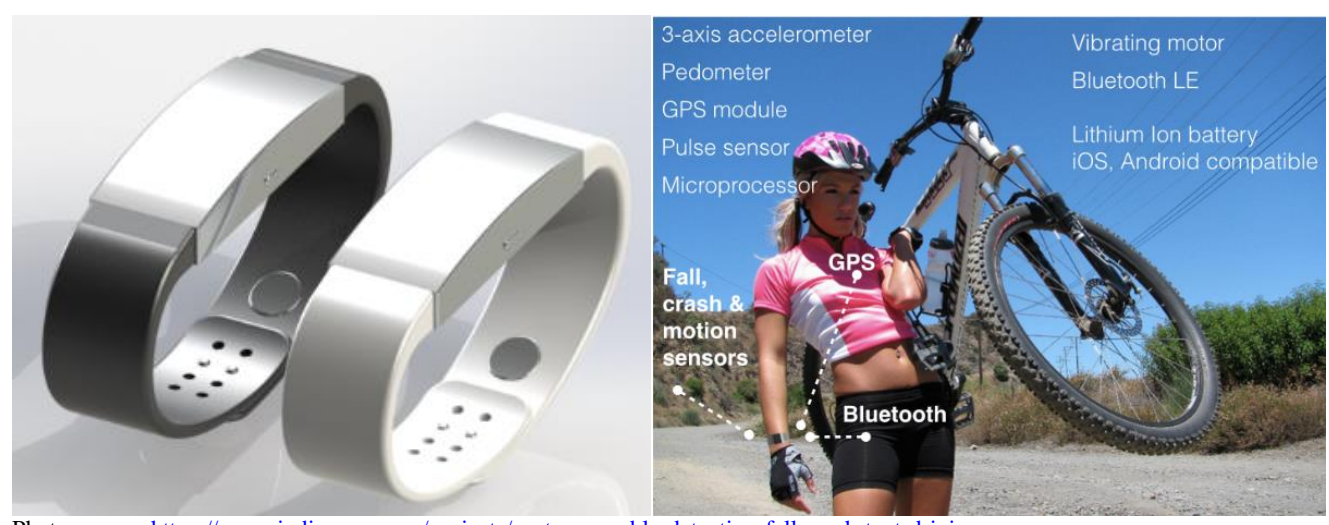

Photo source: https://www.indiegogo.com/projects/grvty-wearable-detecting-fall-crash-text-driving

\subsubsection{Biocompatible Adhesive Gel Patch}

Technology name: Biocompatible adhesive gel patch

Description: Biomedical engineers in Japan developed a "biocompatible, flexible, adhesive gel patch that senses internal or external electrophysiological biological signals." The patch can hold up to 144 sensors placed $4 \mathrm{~mm}$ apart and employs an adhesive gel that holds the detectors in place even on a non-static surface such a limb or joint. The prototype demonstrated that the device "adheres to the wet, dynamic surface of heart muscle for more than 3 hours, facilitating the reliable measurement of biological signals."

Status: Evolving

Funding: 
PNNL RTA Monthly Report - December 2014

Sensors

\section{Product link:}

Source: "Biocompatible Adhesive Gel Patch for Sensing and Monitoring EP Signals in Biological Tissues." FOAM EM RSS. http://www.foamem.com/author/iris-kulbatski/

\subsubsection{Bioserenity: Wearable Epilepsy Monitoring Unit}

Technology name: Wearable Epilepsy Monitoring Unit (WEMU)

Description: The device comprises a shirt and cap with embedded sensors that measure biometric data that are then transmitted to a smartphone, cloud system, and a patient's medical team and/or caretakers.

Status: Evolving

Funding:

Product link: http://www.bioserenity.com/en.html

Source: "Wearable Clothing to Help Epilepsy Patients." Health Tech Insider. http://healthtechinsider.com/2014/12/16/wearable-clothing-help-epilepsy-patients/

\subsection{4 bOMDIC Inc.: GoMore}

Technology name: GoMore

Description: GoMore is a "stamina sensor" employing patented technology that calculates physical capability by providing heart rate analysis and real-time readouts of performance including mileage, stamina, and calorie burn. Features include a heart-rate monitor, real-time alerts, workout map, and efficiency report. The device includes a GoMore sensor, adjustable chest-belt and 24-hour battery life.

Status: Soon to be released. Scheduled release date of April 15, 2015

Funding: Crowdfunding

Product link: http://www.gomore.me/

Source: "World's First Wearable Stamina Sensor And App Changes The Fitness And Health Landscape." $P R$ Newswire. http://www.prnewswire.com/news-releases/worlds-first-wearable-stamina-sensor-and-appchanges-the-fitness-and-health-landscape-300013679.html

\subsubsection{Cambridge Consultants: XelfieX}

Technology name: XelfieX smart fabric

Description: XelfieX employs fiber-optic sensors and impulse radar to measure joint movement. Algorithms translate the sensor data, giving the user feedback on their posture and movement.

Status: Evolving 
PNNL RTA Monthly Report - December 2014

Sensors

\section{Funding:}

Product link: http://www.cambridgeconsultants.com/media/press-releases/innovation-wearable-tech

Source: "New wearable tech really is power dressing." Business Weekly. http://www.businessweekly.co.uk/hi-tech/17906-new-wearable-tech-really-is-power-dressing

\subsubsection{Clevercare}

Technology name: Clevercare medical alarm

Description: Clevercare is a wrist-worn medical alarm that connects patients and caregivers. The device can be used as a communications, alert, and GPS-tracking tool.

Status: Available only in New Zealand.

\section{Funding:}

Product link: http://clevercare.co.nz/

Source: "Wearable device with GPS tracking to provide clever care." Pulse It. http://www.pulseitmagazine.com.au/index.php?option=com_content\&view=article\&id=2210:wearabledevice-with-gps-tracking-to-provide-clever-care \&catid=49:new-zealand-ehealth $\&$ Itemid=329

\subsubsection{Globe: Wearable Advanced Sensor Platform ${ }^{\mathrm{TM}}$}

Technology name: Wearable Advanced Sensor Platform ${ }^{\mathrm{TM}}$ (WASP)

Description: The WASP shirt is equipped with physiological sensors mounted on adjustable straps on a moisture-wicking, flame-resistant shirt. A TRX location unit provides indoor location data in 3D in GPSdenied environments while a Zephyr BioHarness ${ }^{\mathrm{TM}} 3$ electronic module tracks heart rate, heart rate variability, respiration rate, activity levels, posture, and other physiological factors. According to the developer web site, "WASP provides a tool for incident commanders to track the location of team members to improve situational awareness and potentially shorten the time needed for a RIT team to rescue a downed firefighter."

Status: Evolving

\section{Funding:}

Product link: http://www.globeturnoutgear.com/innovations/wasp

Source: Globe Turnout Gear. http://www.globeturnoutgear.com/innovations/wasp 

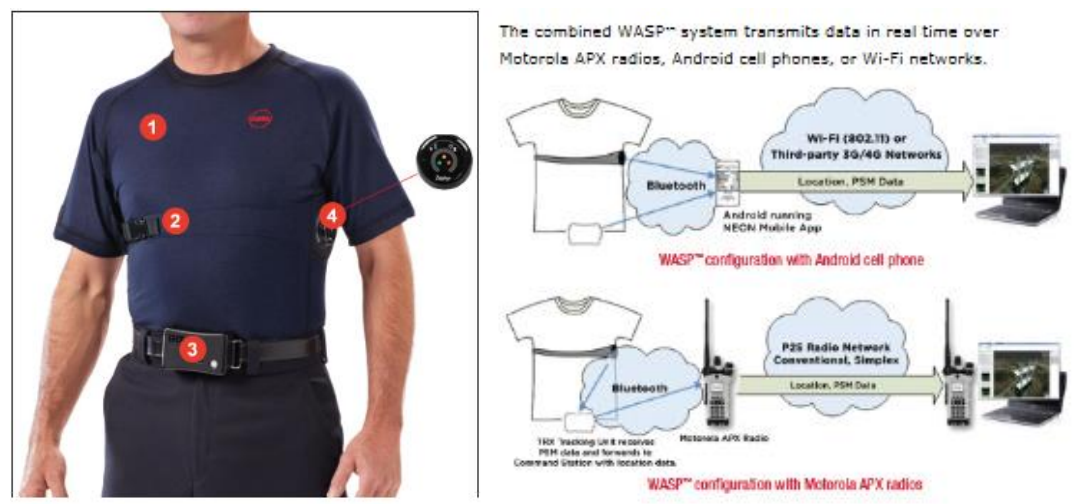

Photo source: http://www.globeturnoutgear.com/innovations/wasp

\subsubsection{Intel, Michael J. Fox Foundation for Parkinson's Research}

Technology name: Wearable technologies to monitor Parkinson's symptoms

Description: The Michael J. Fox Foundation for Parkinson's Research and Intel Corporation are evaluating the use of wearables for tracking physiological features associated with Parkinson's. The developing technology will detect, analyze, and transmit to the cloud mobility patterns in people with Parkinson's disease. According to the Intel press release, scientists are "correlating the data collected to clinical observations and patient diaries to gauge the devices' accuracy, and are developing algorithms to measure symptoms and disease progression."

Status: Evolving

\section{Funding:}

Product link: http://newsroom.intel.com/community/intel newsroom/blog/2014/08/13/the-michael-jfox-foundation-and-intel-join-forces-to-improve-parkinsons-disease-monitoring-and-treatment-through$\underline{\text { advanced-technologies }}$

Source: "Wearable technology is breakthrough for Parkinson's." Israel21c. http://www.israel21c.org/headlines/wearable-technology-is-breakthrough-for-parkinsons/

\subsubsection{Jins Meme}

Technology name: Smart glasses

Description: Smart glasses track eye movement to assess fatigue. The system uses three electrooculography sensors, placed in the frame and nose pads, to measure eye movement and blinking by tracking the retina. The company is exploring applications including "games where eyes would act as the controller, functions to measure interest levels, focus-training exercises and potentially tools to tackle neurodegenerative diseases."

Status: Evolving - anticipated to US market in 2015

\section{Funding:}

Product link: https://www.jins-jp.com/jinsmeme/en/ 
PNNL RTA Monthly Report - December 2014

Sensors

Source: "Jins Meme smart glasses have one eye on fatigue levels." Gizmag. http://www.gizmag.com/jinsmeme-smart-glasses-energy-levels/35317/

Product link: https://www.jins-ip.com/jinsmeme/en/

\subsubsection{Kenzen: $\mathrm{ECHO}^{\mathrm{TM}} \mathrm{H2}$}

Technology name: $\mathrm{ECHO}^{\mathrm{TM}} \mathrm{H} 2$ flexible biochemical sensor

Description: ECHO H2 uses a small, eco-friendly disposable patch to wirelessly analyze a user's sweat to measure hydration, lactic acid, and calories. The device comprises a "printed adhesive biochemical sensor" that communicates via low-energy Bluetooth to smart devices.

Status: Soon to be released - available for pre-order.

Funding: Crowdfunding

Product link: http://www.kenzenwear.com/

Source: "Kenzen Wearable Optimizes Athletic Performance with Real-Time Hydration, Lactic Acid and Glucose Analysis." PR Newswire. http://www.prnewswire.com/news-releases/kenzen-wearableoptimizes-athletic-performance-with-real-time-hydration-lactic-acid-and-glucose-analysis$\underline{300005504 . h t m l}$

\subsubsection{Li Cheng-Yuan, and You Chuang-Wen, National Taiwan University (Individuals): NinjaFlex}

Technology name: NinjaFlex smart bandage

Description: NinjaFlex is a soft 3-D-printer filament, bandage-like material that the National Taiwan University paired with medical sensors that monitor a patient's vital signs and can transmit the data to a patient's medical team using a smartphone or tablet.

Status: Evolving

Funding:

Product link: http://www.ninjaflex3d.com/

Source: "Forget Band-Aid... Here's 'NinjaFlex." Wall Street Daily.

http://www.wallstreetdaily.com/2014/12/17/ninjaflex-smart-bandage/ 
PNNL RTA Monthly Report - December 2014

Sensors

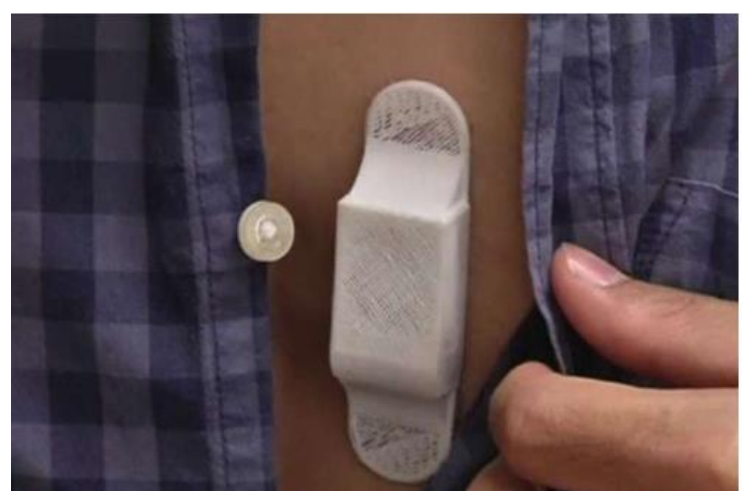

Photo source: http://www.wallstreetdaily.com/2014/12/17/ninjaflex-smart-bandage/

\subsubsection{LifeWatch, Vital Connect: Vital Signs Patch}

Technology name: Vital Signs Patch cardiac telemetry

Description: Vital Signs Patch is a disposable, adhesive, remote cardiac monitoring chest-worn patch that monitors ECG, Heart Rate, respiration rate, surface temperature, and arterial blood oxygen saturation, and also acts as a wireless blood pressure cuff, with an estimated 5-7 day battery life. The device recently received FDA 510(k) clearance. Anticipated applications include, "The patch is immediately applied at the emergency site to capture, analyze and transmit relevant medical data to the hospital."

Status: Soon to be released - expected to launch in late 2015.

\section{Funding:}

Product link: http://www.lifewatch.com/

Source: "LifeWatch gets FDA clearance for adhesive, remote patient monitoring wearable." Mobile Health News. http://mobihealthnews.com/39243/lifewatch-gets-fda-clearance-for-adhesive-remotepatient-monitoring-wearable/

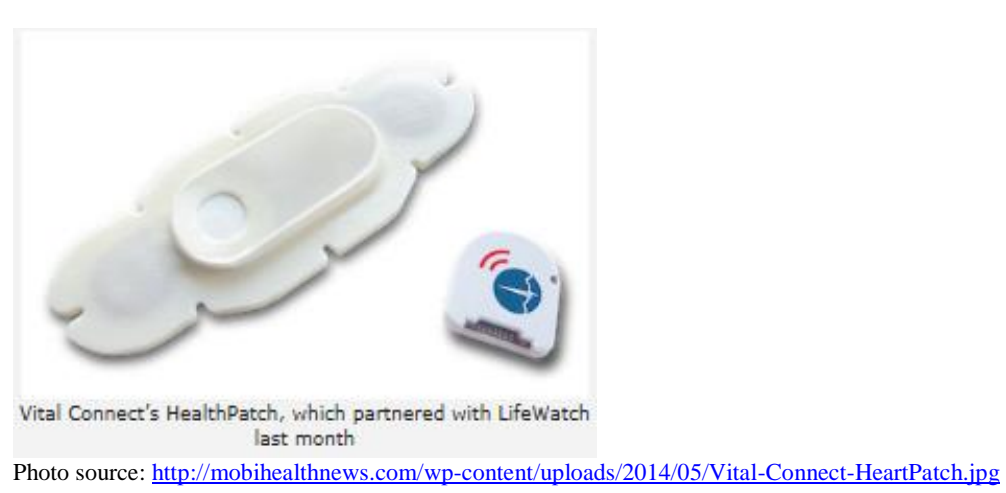

\subsubsection{RipCurl: Search GPS}

Source: "Rip Curl Surf Watch Review: The Most Advanced Waveproof Wearable Yet." Gizmodo India. http://www.gizmodo.in/gadgets/Rip-Curl-Surf-Watch-Review-The-Most-Advanced-WaveproofWearable-Yet/articleshow/45484066.cms 
Product link: http://searchgps.ripcurl.com/welcome/

Technology name: Search GPS smartwatch

Description: This GPS-equipped, water-proof (to 330 feet) wristwatch monitors wave counts and speeds, tracks 1,360 tide locations, and provides notifications to the user. The data can also be used to generate a plot layered on Google Maps satellite image to analyze performance.

Status: Available

Funding:

\subsubsection{Seoul National University}

Technology name: Mechanical sensors

Description: Researchers of Seoul National University are designing a "highly sensitive, durable and flexible spider-inspired mechanical sensors [that] can detect and record music, recognize speech patterns, and monitor heart rates. The researchers are producing a platinum film based on a spider's "crack-shaped slit organs" that detect minute vibrations. The highly sensitive device "is reversible, reproducible, durable and mechanically flexible, and can thus be easily mounted on human skin as an electronic multipixel array."

Status: Evolving

\section{Funding:}

Product link: http://nature.com/articles/doi:10.1038/nature14002

Source: "Scientists Built a Wearable Sensor Pack Based on Spider Senses." Business Insider Australia. http://www.businessinsider.com.au/a-wearable-sensor-pack-based-on-spider-senses-2014-12

\subsubsection{Spire}

Technology name: Spire sensor clip

Description: Spire clips onto a user's garments worn close to the body and tracks breathing patterns to measure and notify a user of his/her focus, tension, calm, and activity.

Status: Available

\section{Funding:}

Product link: $\underline{\text { https://spire.io/ }}$

Source: "This Gadget Hooks Onto Your Underwear and Helps You Chill Out." The Huffington Post. http://www.huffingtonpost.com/2014/12/16/spire-wearable_n_6329888.html 
PNNL RTA Monthly Report - December 2014

Sensors

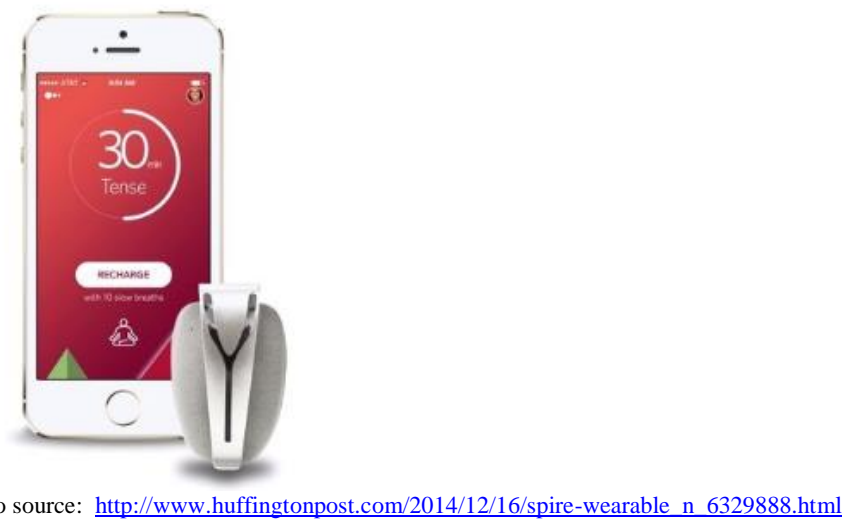

\subsubsection{University of Massachusetts Amherst, GE}

Technology name: Patch to measure biomarkers in sweat

Description: Nano-Bio Manufacturing Consortium (backed by U.S. Air Force Research Laboratory) selected a proposal by the University of Massachusetts, Amherst, to develop a wearable sensor patch that monitors chemicals in the user's sweat to indicate stress and fatigue. The system targets Orexin-A, "a naturally occurring neuropeptide hormone released by the hypothalamus, and plays a crucial role in the stability of arousal and alertness." According to the NMBC press release, the technology demonstrated detection of Orexin-A from blood and saliva samples and offers the "lowest-risk system integration."

Status: Evolving

Funding: Awarded $\$ 450,000$ funding - 50\% from NBMC's U.S. Air Force Research Laboratory funds and $50 \%$ will be contributed by the winning team of UMass Amherst and its industrial partner, GE.

Product link: http://www.nbmc.org/nano-bio-manufacturing-consortium-selects-wearable-sensor-patchsubsystem-project-as-first-to-receive-funding/

Source: "Cheap, Disposable Biometric Patch to Monitor Stress and Fatigue in Military Personnel May Be Adapted to Monitor Biomarkers Used by Clinical Pathology Laboratories." Dark Daily. http://www.darkdaily.com/cheap-disposable-biometric-patch-to-monitor-stress-and-fatigue-in-militarypersonnel-may-be-adapted-to-monitor-biomarkers-used-by-clinical-pathology-laboratories1210\#axzz3Py16G6zZ

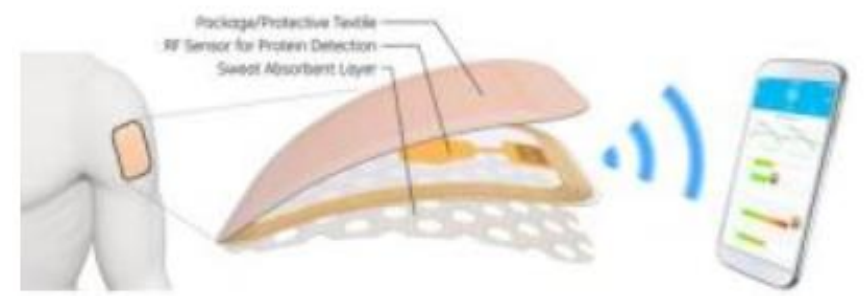

Photo source: http://www.darkdaily.com/cheap-disposable-biometric-patch-to-monitor-stress-and-fatigue-in-military-personnel-may-be-adapted-to-monitorbiomarkers-used-by-clinical-pathology-laboratories-1210\#axzz3Py16G6zZ 


\subsubsection{UC Berkeley}

Technology name: Pulse oximeter sensor

Description: This organic-based wearable tracks blood-oxygen levels and measures pulse rate. Berkeley researchers describe the technology as using "light-emitting diodes (LEDs) to send red and infrared light through a fingertip or earlobe. Sensors detect how much light makes it through to the other side. Bright, oxygen-rich blood absorbs more infrared light, while the darker hues of oxygen-poor blood absorb more red light. The ratio of the two wavelengths reveals how much oxygen is in the blood."

Status: Evolving

Funding: National Science Foundation and Flextech helped support this research

\section{Product link:}

Source: "Organic electronics could lead to cheap, wearable medical sensors." UC Berkeley News Center. http://newscenter.berkeley.edu/2014/12/10/organic-electronics-cheap-wearable-medical-sensors/

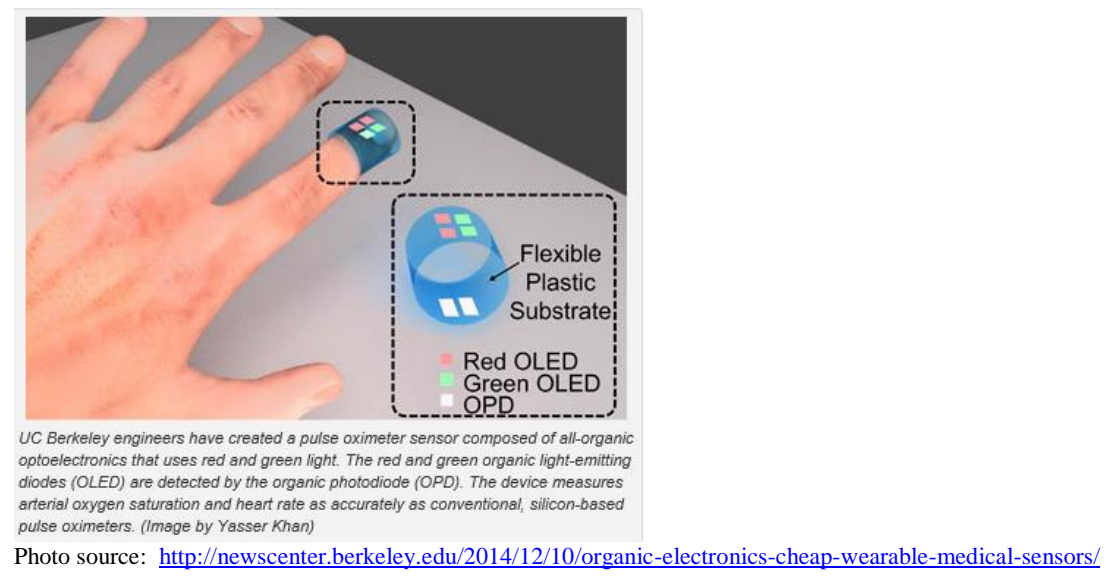

\subsubsection{U-Wake}

Technology name: U-Wake headband

Description: The U-Wake headband uses EEG sensors to monitor brainwaves and analyze fatigue level because "brainwaves of a sleeping person are different from the brainwaves of a person who is awake." The device communicates to a smartphone app via Bluetooth.

Status: Evolving

Funding: Crowdfunding

Product link: http://u-wake.com/

Source: "Wake Up! Wearable Biomonitor Keeps You Safer While Driving." PSFK. at http://www.psfk.com/2014/12/biomonitor-aimed-at-driver-safety.html 
PNNL RTA Monthly Report - December 2014

Sensors

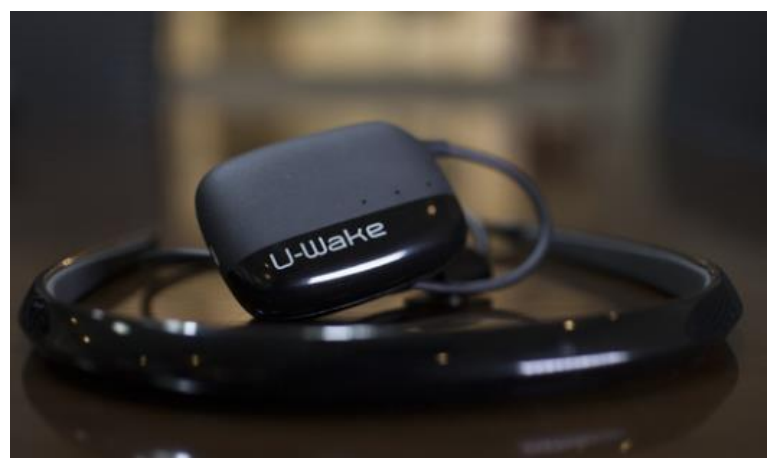

Photo source: https://www.kickstarter.com/projects/441115504/u-wake-your-guardian-angel-for-road-safety

\subsubsection{VivaLnk: eSkin ${ }^{\mathrm{TM}}$ Thermometer}

Technology name: eSkin ${ }^{\mathrm{TM}}$ Thermometer

Description: eSkin ${ }^{\mathrm{TM}}$ uses electronic circuitry with embedded sensors on a thin, flexible material that comfortably adhere to the skin to measure temperature. The device employs a near-field communications (NFC) chip from NXP Semiconductors, does not require a battery, and transmits information to a smartphone app for "record keeping and alert function."

Status: Evolving

Funding: A limited number of samples will be available for interested partners in January 2015.

Product link: http://www.vivalnk.com/

Source: "VivaLnk Showcases New Wearable Thermometer Patch Based on Breakthrough eSkin" Technology at CES." http://www.vivalnk.com/vivalnk-showcases-new-wearable-thermometer-patchbased-breakthrough-eskintm-technology-ces/

\subsubsection{WiseWear: Evolve ${ }^{\mathrm{TM}}$}

Technology name: Evolve

Description: Evolve uses the Nomad core sensor platform in a chest strap, shirt clip, or wristband to track heart rate, respiration, motion, global movement, galvanic skin response, and blood oxygenation and transmitted to a mobile device. The system employs predictive algorithms and analytics to interpret the data.

Status: Soon to be released - anticipated $4^{\text {th }}$ quarter of 2015

Funding: Crowdfunding

Product link: http://wisewear.com/

Source: WiseWear Evolve: Wearable 2.0 Sensor Platform. https://www.indiegogo.com/projects/wisewear-evolve-wearable-2-0-sensor-platform 
PNNL RTA Monthly Report - December 2014

Sensors

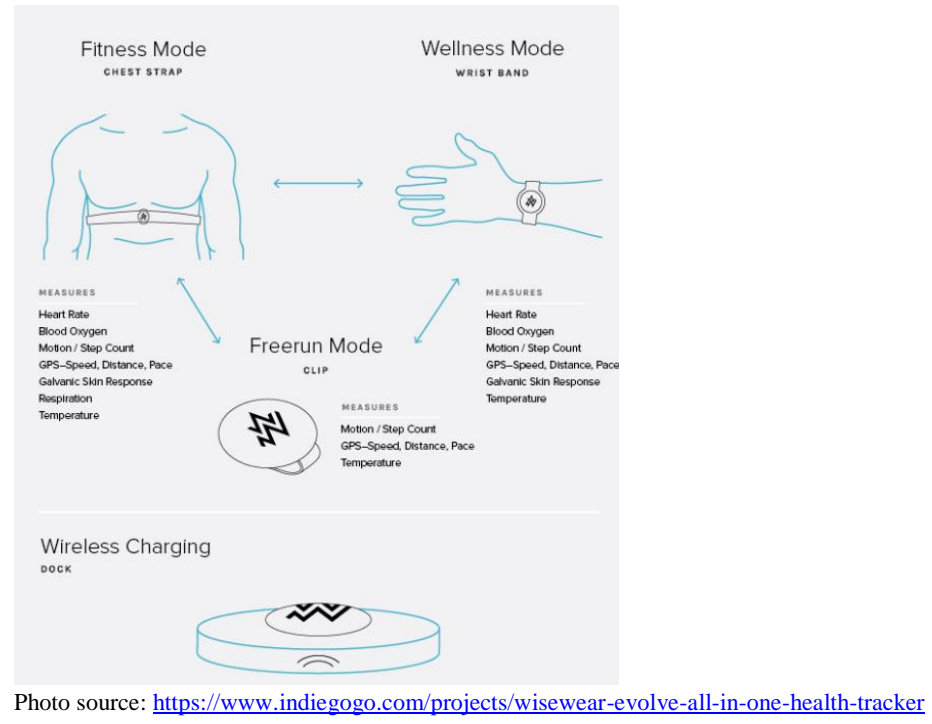

\subsection{Chemical/Particulate}

\subsubsection{Breathe}

Technology name: Breathe

Description: Breathe employs air quality sensors in a wearable clip to measure toxic elements in the air and report a user's air pollution readings to crowdsourced dataset. The device can also send air pollution alerts to a user's smartphone.

Status: Evolving

\section{Funding:}

Product link: http://breathe.city/

Source: "Wearable air quality monitor crowdsources pollution data." Springwise. http://www.springwise.com/wearable-air-quality-monitor-crowdsources-pollution-data/ 


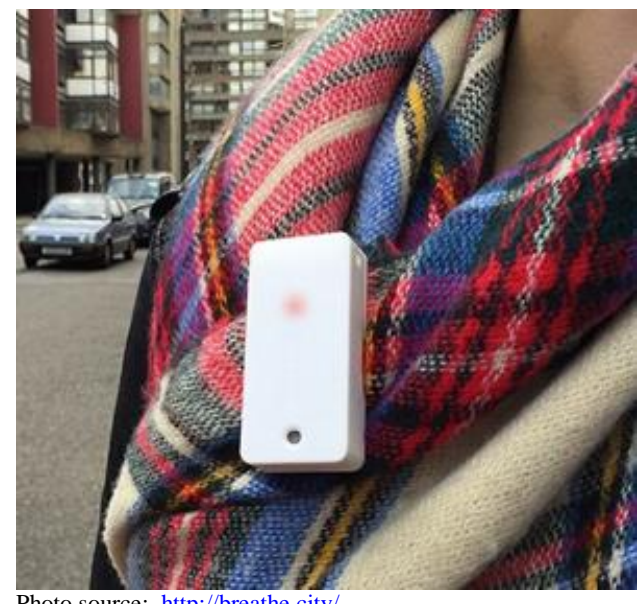

Photo source: http://breathe.city/

\subsubsection{Wepo}

Technology name: Wepo air pollution monitor

Description: Wepo is a wearable pollution-exposure-monitoring device equipped with an electrochemical carbon monoxide sensor. Future iterations are expected to measure nitrogen dioxide, particulate matter and other pollutants. The device features a 20 -hour battery life and communicates with phone apps to interpret the air pollution data.

Status: Evolving

Funding: Crowdfunding - surpassed target

Product link: https://www.indiegogo.com/projects/wepo-for-people-who-watch-air

Source: "Wepo is a Crowdfunded Wearable for Air Quality Monitoring." NDTV Gadgets.

http://gadgets.ndtv.com/wearables/news/wepo-is-a-crowdfunded-wearable-for-air-quality-monitoring$\underline{639560}$

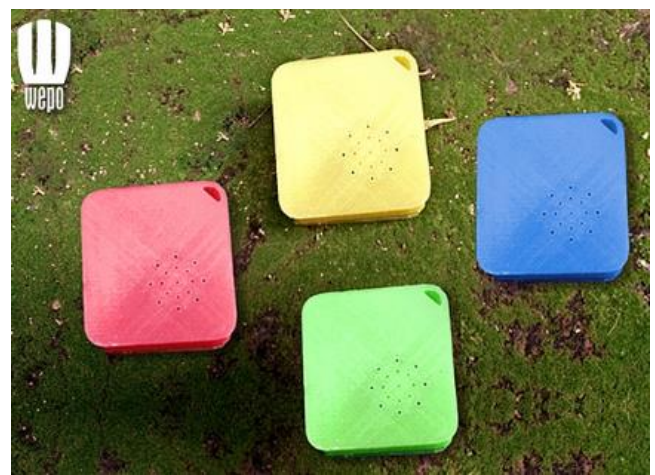

Photo source: https://www.indiegogo.com/projects/wepo-for-people-who-watch-air 
PNNL RTA Monthly Report - December 2014

Sensors

\subsection{Other}

\subsubsection{First Sign, MaceWear: Pod}

Technology name: 5-in-1 Pod automatic personal security system

Description: The Pod provides "advanced software and sensors to automatically detect many violent assaults or medical emergencies." The device attaches to common devices such as a keychain, belt clip, wristband, pendant or headband, and serves as an assault alert, fall alert, and panic button. Depending on where it is worn, it can detect when a user suffers a blow or administers a self-defense maneuver, for example. It collects "evidence" (location, what happened, photographs) and blares and alarm.

Status: Available

\section{Funding:}

Product link: http://www.firstsign.us/

Source: "First Sign and MaceWear Launch Pod: the Crime-Fighting Wearable." Wearable World News. http://wearableworldnews.com/2014/12/09/first-sign-macewear-launch-pod-crime-fighting-wearable/

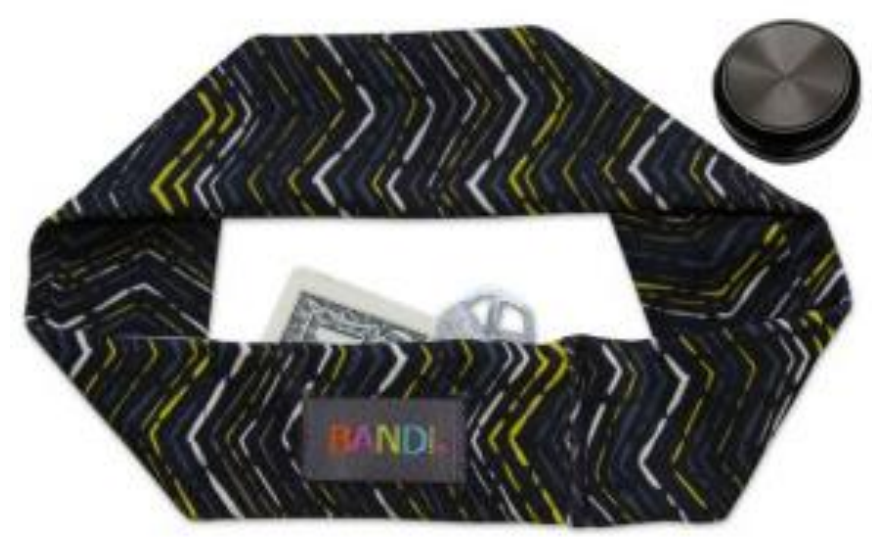

Photo source: http://www.firstsign.us/products/\#/pod/

\subsubsection{Pauline van Dongen and TU Eindhoven \& Textile Museum: Vigour}

Technology name: Vigour clothing for rehabilitation and physical therapy

Description: Vigour clothing, with knit stretch sensors, was designed by Pauline van Dongen and TU Eindhoven \& Textile Museum to track a user's movements and make the data available to a mobile app for use by the patient, therapist, caretakers, etc., with intended applications in rehabilitation and physical therapy.

Status: Evolving

Funding: 
PNNL RTA Monthly Report - December 2014

Sensors

Product link: http://paulinevandongen.nl/news/vigour/

Source: "Vigour Wearable Tech For Rehabilitation \& Physical Therapy." Ubergizmo. http://www.ubergizmo.com/2014/12/vigour-wearable-tech-for-rehabilitation-physical-therapy/

\subsubsection{ReTiSense: Stridalyzer}

Technology name: Stridalyzer smart insoles

Description: Stridalyzer uses insoles equipped with patent-pending technology of multiple sensors that communicate stride information to a smart device. The device is intended to help users collect data about motion dynamics (stride, foot landing, etc.) and interpret the information with cloud-based analytics.

Status: Soon to be released

Funding: Crowdfunding

Product link: http://www.retisense.com/

Source: "Stridalyzer: World's First Wearable Product to Predict Knee Injury Risk, Live on Kickstarter." PRWeb. http://www.prweb.com/releases/2014/12/prweb12395982.htm

\subsubsection{Torch}

Technology name: Torch

Description: Torch uses infrared sensors worn on the head or chest that emit an audible or vibrating warning when the user approaches an obstacle.

Status: Evolving

Funding:

Product link:

Source: "Wearable Sensor 'Illuminates' Surroundings for the Blind.” http://on.aol.com/video/wearablesensor-illuminates-surroundings-for-the-blind-518553057?playlist $=165852 \& \mathrm{hp}=1$

\subsubsection{Triax SIM-P}

Source:"Triax SIM-P: Smart Wearable Monitors Head Impact.” iPhoneness.

http://www.iphoneness.com/cool-finds/triax-sim-p/

Product link: https://www.triaxtec.com/sim-p/

Technology name: Triax SIM-P head band

Description: Triax SIM-P fits into a headband or cap and measures G-force of head impacts and sends alerts to smart devices. 
PNNL RTA Monthly Report - December 2014 Sensors

Status: Available

\section{Funding:}

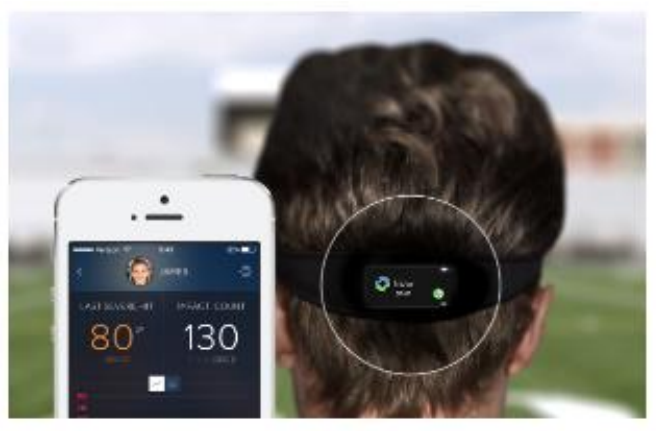

Photo source: http://www.iphoneness.com/cool-finds/triax-sim-p/ 

PNNL RTA Monthly Report - December 2014

Displays

\subsection{Displays}

\subsection{Heads-up (on face or head)}

\subsubsection{Intel, Luxottica Group}

Technology name: Smart sports eyewear

Description: Intel Corporation and Luxottica Group S.p.A announced a multiyear collaboration to "fuse premium, luxury and sports eyewear with smart technology."

Status: Evolving - first product expected to launch in 2015

\section{Funding:}

\section{Product link:}

Source: "Intel and Luxottica Group Announce Multiyear Collaboration for Wearable Tech." http://newsroom.intel.com/community/intel_newsroom/blog/2014/12/03/intel-and-luxottica-groupannounce-multiyear-collaboration-for-wearable-tech

\subsubsection{Microsoft}

Technology name: Virtual reality headset

Description: In line with Sony's Project Morpheus and Oculus Rift, Microsoft is anticipated to unveil a virtual reality headset at the E3 conference in June 2015.

Status: Evolving - anticipated in 2015

Funding:

Product link:

Source: "Microsoft's working on a wearable VR headset!" The Gadget Show.

http://gadgetshow.channel5.com/news/microsoft\%E2\%80\%99s-working-wearable-vr-headset

\subsubsection{Oculus VR}

Technology name: Oculus virtual reality (VR)

Description: Oculus announced three acquisitions/partnerships: Nimble VR, 13th Lab, and Chris Bregler, motion expert, to "the best and brightest in the space to solve some of the hardest vision challenges facing [virtual reality]." Nimble VR has been working on "high-quality, low-latency skeletal hand tracking," and "machine learning and computer vision capabilities." 13th Lab has been developing "real-time 3D reconstructions" of real-world sights. Bregler has been focused on visual tracking. 
PNNL RTA Monthly Report - December 2014

Displays

Status:

Funding:

Product link: https://www.oculus.com/blog/nimble-vr-13th-lab-and-chris-bregler-join-oculus/

Source: “Oculus VR Buys Hand-Tracking, 3D-Modeling Firms.” PCMag UK.

http://uk.pcmag.com/wearable-tech/38211/news/oculus-vr-buys-hand-tracking-3d-modeling-firms

\subsubsection{Osterhout Design Group}

Technology name: Smart glass platform

Description: Osterhout is developing a "smart-glass platform capable of running full Android tablet software and extraordinarily crisp optics, which seem to float in front of the users' eyes even though the lenses on the glasses are clear."

Status: Soon to be available - expected to ship next year

Funding: Osterhout has reportedly invested about $\$ 60$ million.

Product link: http://www.osterhoutgroup.com/company

Source: "Business puts on its wearables: Techies see limitless potential in data-rich gadgets." Upstart Business Journal. http://upstart.bizjournals.com/companies/innovation/2014/12/07/wearable-tech-googleglasses-pebble-watch-myo.html?page=all

\subsubsection{Sony: Single-Lens Display Module}

Technology name: Single-Lens Display Module

Description: According to the Sony blog, the module "turns eyewear into a smart device capable of displaying visual information" via a high-resolution color OLED microdisplay and miniaturized control board. The device beams the visual onto the user's glasses.

Status: Evolving - anticipated to be mass producing the module in the coming year

\section{Funding:}

Product link: http://www.sony.net/SonyInfo/News/Press/201412/14-118E/index.html

Source: "Sony concept eyewear tech turns your existing specs into smartglasses." CNET. http://www.cnet.com/news/sony-concept-eyewear-tech-turns-your-existing-specs-into-smartglasses/ 
PNNL RTA Monthly Report - December 2014

Displays

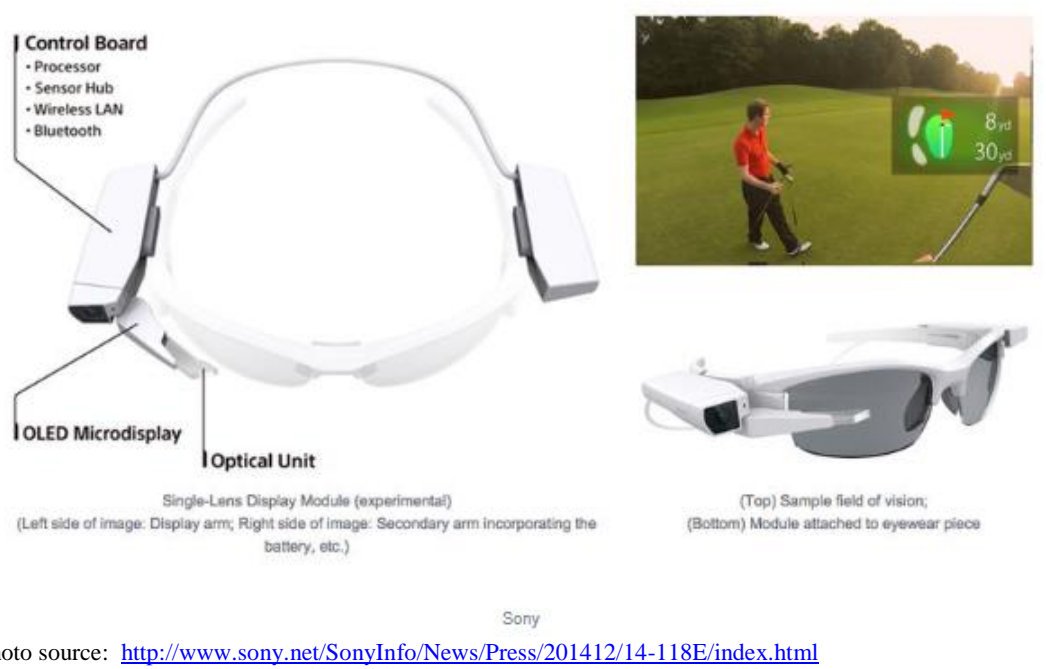

\subsection{Body-worn (wrist, arm, or chest)}

\subsubsection{Honeywell}

Technology name: Wearable Solution for the Dolphin 70e Mobile Computer

Description: The device is a "hands-free, wrist-mounted version of the Dolphin 70e Black mobile device" intended to support warehouse operations. The device includes a large display and flexible touchscreen keypad.

Status: Soon to be released - anticipated to begin shipping in Asia Pacific in December.

\section{Funding:}

Product link: https://www.honeywellaidc.com/en-us/Pages/Product.aspx?category=wearable-scannerand-mobile-computer\&cat=HSM\&pid=wearablesolution

Source: "Transforming DC operations with new technology." Transport and Logistics News. http://www.tandlnews.com.au/2014/12/04/article/transforming-dc-operations-new-technology/

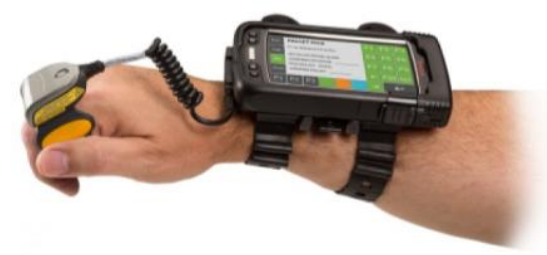

Photo source: http://www.tandlnews.com.au/2014/12/04/article/transforming-dc-operations-new-technology/data-capture-honeywell-wearable-device/ 


\subsubsection{Google, Intel: Google Glass v2}

Technology name: Google Glass

Description: This article explores the possibilities of Intel being integrated into the upcoming iteration of Google Glass, in particular "divorcing advanced processing of things like speech from the cloud, and instead making such functionality self-contained" as well as "less reliance on a wireless connection and less time with the power-hungry screen."

Status: Evolving

\section{Funding:}

\section{Product link:}

Source: "Here's why Intel makes perfect sense for Google Glass v2." Slash Gear.

http://www.slashgear.com/heres-why-intel-makes-perfect-sense-for-google-glass-v2-01357860/ 
PNNL RTA Monthly Report - December 2014

Power

\subsection{Power}

\subsection{Chargers}

\subsubsection{SolarHug}

Technology name: SolarHug bracelet

Description: SolarHug is a bracelet that transforms solar energy into power for a smartphone or other devices via USB.

Status: Evolving

Funding: Crowdfunding

Product link: http://solarhug.com/

Source: "SolarHug Bracelet - Wearable Solar Charger." Energy Matters.

http://www.energymatters.com.au/renewable-news/solarhug-bracelet-charger-em4615/

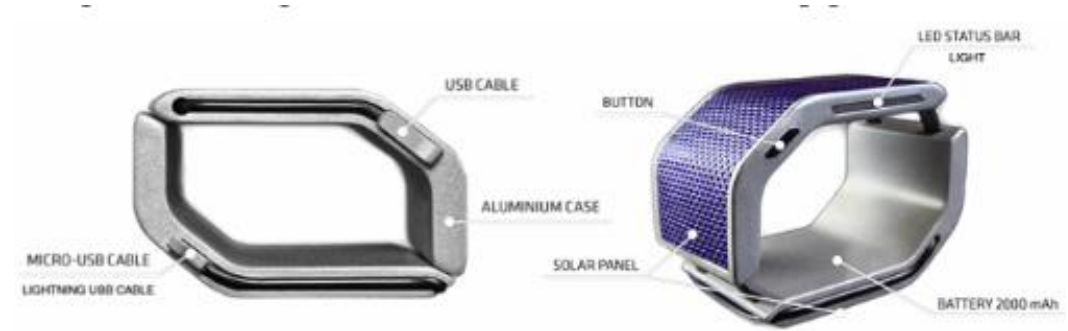

Photo source: https://www.kickstarter.com/projects/1609919685/solarhug-bracelet-external-charger-powered-by-the

\subsection{Self-powering (Harvesters)}

\subsubsection{Lanzhou University, Chinese Academy of Sciences}

Technology name: Wearable triboelectric generator

Description: Researchers with the Lanzhou University and Chinese Academy of Sciences are designing a "cloth-based wearable triboelectric nanogenerator made of nylon and Dacron fabric" that harvests body motion energy. For example, the device "can turn the mechanical energy of [an] arm swing into electric energy and power an electroluminescent tube-like lamp easily." The device can output up to $0.2 \mathrm{~mA}$ and $2 \mathrm{kV}$ and be handled like a normal garment.

Status: Evolving

Funding: Support from the NSFC, Fok Ying Tung education foundation, and Fundamental Research Funds for the Central Universities. 
PNNL RTA Monthly Report - December 2014

Power

\section{Product link:}

Source: Cui N, J Liu, L Gu, S Bai, X Chen, and Y Qin. 2014. "Wearable Triboelectric Generator for Powering the Portable Electronic Devices." ACS Applied Materials \& Interfaces. Accessed January 26, 2015 at http://pubs.acs.org/doi/pdfplus/10.1021/am5071688

\subsubsection{Natick Soldier Research, Development, and Engineering Center}

Technology name: Soldier-worn power sources

Description: Researchers are exploring portable, energy-harvesting technologies to reduce the need for soldiers to carry extra batteries. These devices capture "small amounts of energy that would otherwise be lost as heat, light, sound, vibration or movement" to recharge or power devices (communication equipment, sensors, displays). Researchers demonstrated the concept in April, including MC-10's photovoltaic wearable Solar Panel, Harvester Bionic Power's Knee Harvester, and the Lightning Pack's Rucksack. The device is "capable of producing 16 to 22 watts while walking, and 22 to 40 watts while running."

Status: Evolving - prototype was tested at Maneuver Fires Integration Experiment (MFIX) in September 2014

\section{Funding:}

Product link:

Source: "Soldiers of the Future to Self-generate Power." Armed with Science: The Official U.S. Defense Department Science Blog. http://science.dodlive.mil/2014/12/22/soldiers-of-the-future-to-self-generatepower/

\subsubsection{Texas Instruments}

Technology name: Harvesting technology

Description: Texas Instruments is developing electronics that turn small amounts of power generated by harvested sources into useful power sources. Texas Instruments demonstrating the ability to draw energy from the human body through vibration collectors or other harvesters the size of a wristband.

Status: Evolving

\section{Funding:}

Product link: http://www.ti.com/

Source: "Texas Instruments builds an alternative energy for the Internet of Things" Computer World. http://www.computerworld.com/article/2861863/texas-instruments-builds-an-alternative-energy-for-theinternet-of-things.html 


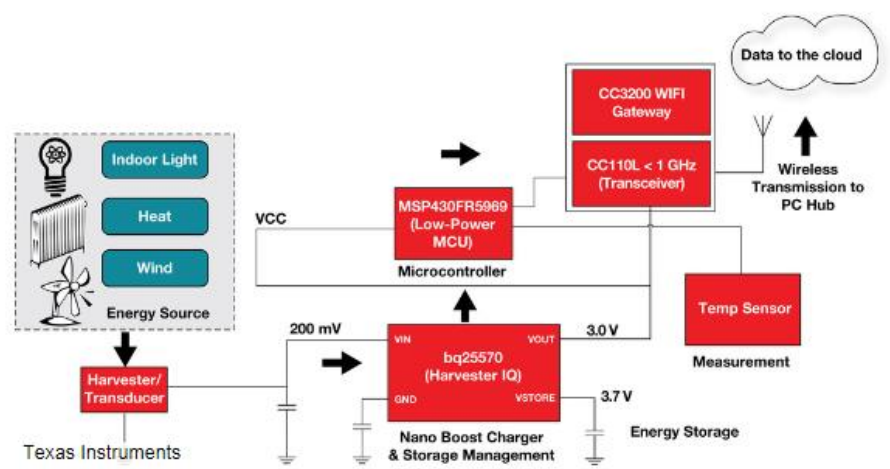

The diagram shows how Texas Instrument's wireless sensor network would work.

Photo source: http://www.computerworld.com/article/2861863/texas-instruments-builds-an-alternative-energy-for-the-internet-of-things.html

\subsection{Power supplies}

\subsubsection{Fujitsu Laboratories Ltd.}

Technology name: Middleware

Description: Fujitsu Laboratories is developing sensing middleware that will "simplify development of low-power sensing applications," by essentially intercepting requests for notification from applications, thus reducing the power drain on wearables and reducing the customizing work and associated development cycles and costs. The technology "cuts the amount of work required to build solutions that use sensing by $90 \%$, while reducing power requirements by more than two-thirds."

Status: Evolving - aiming for implementation during fiscal 2015.

\section{Funding:}

Product link: http://www.fujitsu.com/us/products/software/middleware/

Source: "Fujitsu laboratories develops sensing middleware to simplify development of low-power sensing applications." Phys.org. http://phys.org/news/2014-12-fujitsu-laboratories-middleware-lowpower-applications.html

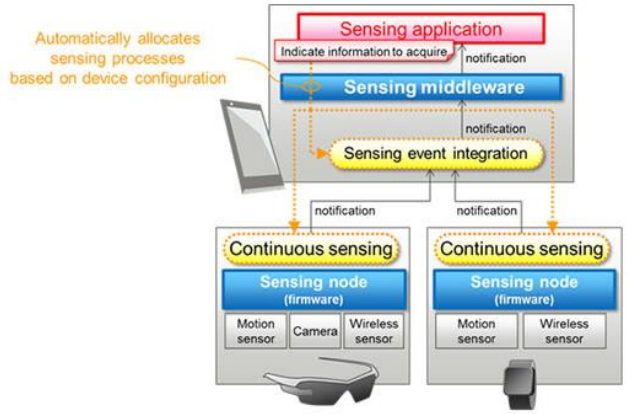

Figure 2: Overview of sensing application development framework

Photo source: http://phys.org/news/2014-12-fujitsu-laboratories-middleware-low-power-applications.html 

PNNL RTA Monthly Report - December 2014

Communications

\subsection{Communications}

\subsection{Integrated voice/data/video}

\subsubsection{Telepathy Inc.: Jumper}

Technology name: Jumper

Description: Jumper is a neck-worn and eye-worn device that features an optical display, camera, microphone, and sensors and is planned to have two applications, Eye Connect and Talent Buzz, that allow the user to share their field of vision and other information with others.

Status: Soon to be available - expected to go on sale in summer of 2015

\section{Funding:}

Product link: http://tele-pathy.org/eng/product/index.php

Source: "Presenting 'Telepathy Jumper,' a wearable device that alters how people communicate by sharing experiences." PRNewswire. http://www.prnewswire.com/news-releases/presenting-telepathyjumper-a-wearable-device-that-alters-how-people-communicate-by-sharing-experiences-300013429.html

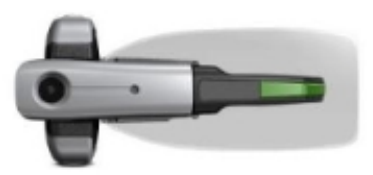

Photo source: http://www.telepathywear.com/product/index.php

\subsection{Short-range low-power Bluetooth}

\subsubsection{Alpha: NFC ring}

Technology name: Titanium near-field communication (NFC) ring

Description: This NFC ring communicates with other NFC devices, allowing the user to unlock NFCenabled doors, communicate with NFC-enabled phones, and transfer information. It features open-source software allowing users to customize their experience.

Status: Available

Funding:

Product link: http://store.nfcring.com/products/alpha-signature

Source: "Alpha Titanium NFC Ring." Cool Wearable. http://www.coolwearable.com/alpha-titanium-nfcring/ 
PNNL RTA Monthly Report - December 2014

Communications

\subsubsection{Caseco: Blu-Toque}

Technology name: Blu-Toque dual-layered Bluetooth hat

Description: Blu-Toque is a beanie (hat) equipped with Bluetooth technology that allows the user to take calls, listen to music, etc. wirelessly and without headphones. The device has a 10-meter range and charges in 2 hours for a 6-hour battery life.

Status: Available

Funding:

Product link: http://www.caseco.ca/product/blu-toque/

Source: Caseco Blu-Toque. http://www.caseco.ca/product/blu-toque/

\subsection{Hands-Free Operations}

\subsubsection{Fin}

Technology name: Fin thumb ring

Description: Fin is a smart thumb ring that utilizes Bluetooth and allows the user to engage with smart devices and appliances to share information and communicate.

\section{Status:}

Funding: Crowdfunding

Product link: http://mydreamistechnology.blogspot.com/2014/12/Fin-advanced-thumb-wearable.html

Source: "Fin advanced gesture-based thumb wearable." http://vimeo.com/114437753

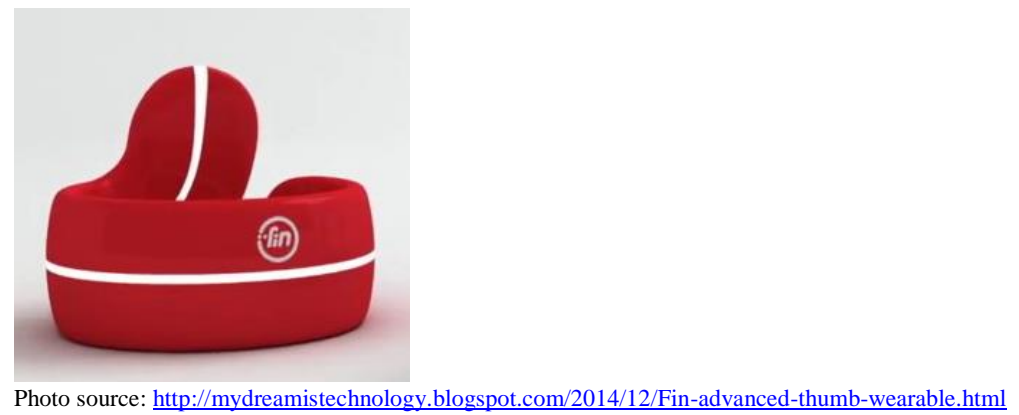




\subsubsection{Fullpower}

Technology name: MotionX Sensor-Fusion technology

Description: Fullpower ${ }^{\circledR}$ was awarded a patent $(8,902,154)$ for motion and gesture control in wearable devices, supplementing the company's MotionX Sensor-Fusion technology. Fullpower's MotionX® and Sleeptracker® technologies are featured in leading wearable devices including Nike and Jawbone.

Status: Available

\section{Funding:}

Product link: http://www.fullpower.com/

Source: "Fullpower Awarded Motion and Gesture Control Patent Critical for Wearable Devices." http://fullpower.com/news/2014/fullpower-awarded-motion-and-gesture-control-patent-critical-forwearable-devices/

\subsubsection{Institute for Integrative Nanosciences, Institute for Solid State and Materials Research Dresden, et al.}

Technology name: Flexible magnetic field sensors

Description: Researchers are developing flexible bismuth Hall sensors that can bend around the wrist or be positioned on the finger, with only a minor reduction in sensor performance, and create an interactive pointing device for wearable devices.

Status: Evolving

Funding: Financed in part by the German Research Foundation DFG, BMBF project Nanett, and European Research Council within the European's Seventh Framework Program

\section{Product link:}

Source: "Wearable Magnetic Field Sensors for Flexible Electronics." Advanced Materials. http://onlinelibrary.wiley.com/doi/10.1002/adma.201405027/abstract

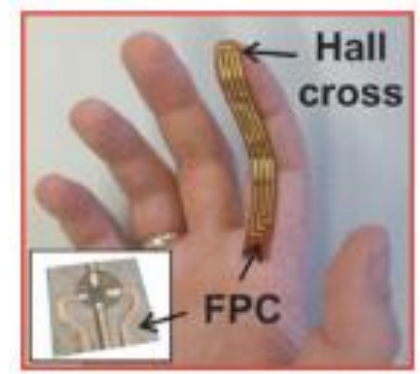

Photo source: http://onlinelibrary.wiley.com/doi/10.1002/adma.201405027/pdf 



\subsection{Exoskeletons}

\subsubsection{Argo}

Technology name: Kineseowear, Ouijaband, LaLaLa

Description: This article explores upcoming technologies and advances in the areas of wearable technology available by Argo. For example, Kineseowear delivers cues to the wearer and resembles "a cross between a pair of suspenders and a small backpack and uses physical pressure to act as physical cues to action;" the Ouijaband uses a gyroscope and high RPM flywheels to steady a user's hand or grip; and Argo's LaLaLa uses a camera, microphone, Bluetooth, and gesture recognition to help the user focus in on what they want to (or do not want to) hear or see.

Status: Evolving

\section{Funding:}

Product link: http://www.argodesign.com/wearables.html

Source: "New Wearable Technology: 'Extra Muscles For Better Performance."” Agriculture. http://www.agriculture.com/news/technology/new-wearable-technology-extra-muscles-f_6-ar46554
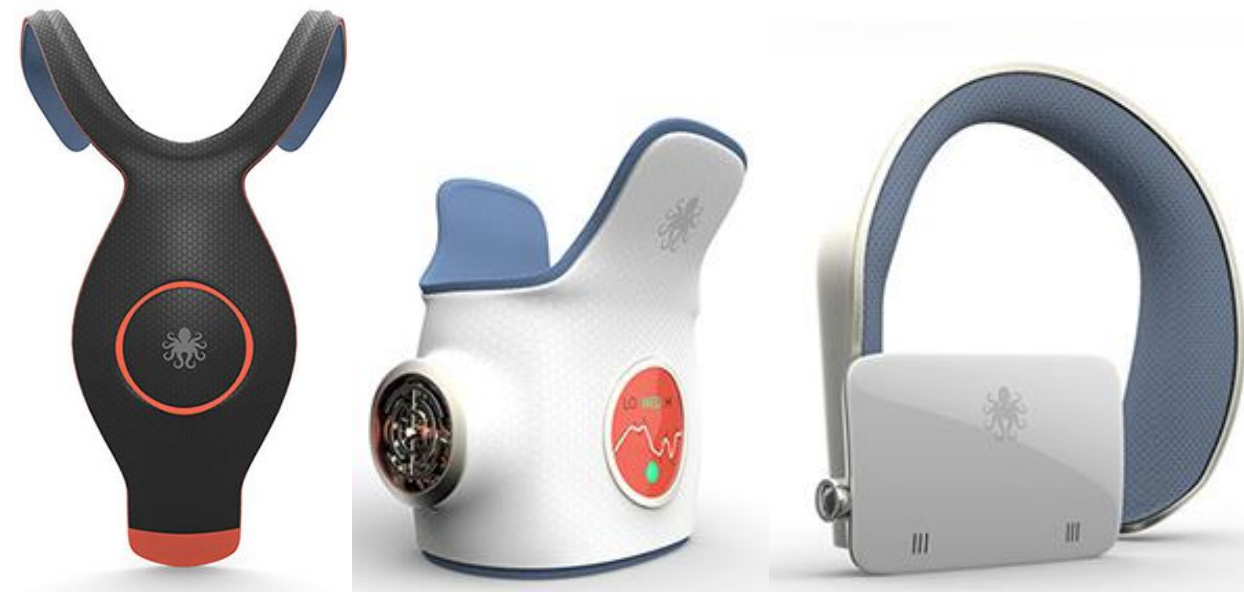

Photo source: http://www.argodesign.com/wearables.html

\subsubsection{Daewoo Shipbuilding and Marine Engineering}

Technology name: Robotic suit

Description: Daewoo is testing exoskeleton suits of light-weight aluminum alloy and steel, with straps at the feet, thigh, waist, and chest, and comprising hydraulic joints and electric motors connected to a backpack that powers the robotic suit. The suit is reported to "help workers lift up to $30 \mathrm{~kg}$, but the creators believe that they can increase that to a potential $100 \mathrm{~kg}$."

Status: Evolving 


\section{Funding:}

Product link: http://www.dsme.co.kr/epub/main/index.do

Source: "Wearable robotics shows promise for heavy manufacturing." EET India. http://www.eetindia.co.in/ART 8800707957 1800001_NT 71104356.HTM

\subsubsection{Defense Advanced Research Projects Agency (DARPA): Airlegs}

Technology name: Airlegs

Description: Airlegs are powered by a tank of compressed air connecting pulleys and electronic sensors to braces that essentially help pull the user's legs. The device currently reduces the user's load by 10 percent, with a goal to reach 25 percent.

Status: Evolving

\section{Funding:}

Product link: http://www.darpa.mil/default.aspx

Source: "An entire platoon wearing wearable robots." CBS News.

http://www.cbsnews.com/news/militarys-darpa-lab-creates-wearable-robot-to-help-soldiers-run-faster/ 


\subsection{Wearable Computers}

\subsubsection{UK Home Office}

Technology name: Police officer wearables

Description: This article explores how wearable technology is being considered to enhance police safety and operations. This includes body cameras, light-weight armor, graphene material, smart watches, digital glasses, and exoskeletons. The UK Minister for Organised Crime announced the launch of the Security Innovation Centre (SIDC) where scientists are "developing the digital police officer" to maximize capabilities of wearable technologies.

Status: Evolving

\section{Funding:}

\section{Product link:}

Source: "Robocops! How Google Glass, wearable computers and exoskeletons will turn the friendly neighbourhood bobby into a 'paramilitary' crime-fighting machine." Daily Mail. http://www.dailymail.co.uk/news/article-2875775/Robocops-Google-Glass-wearable-computersexoskeletons-police-forces-wishlists-officers.html

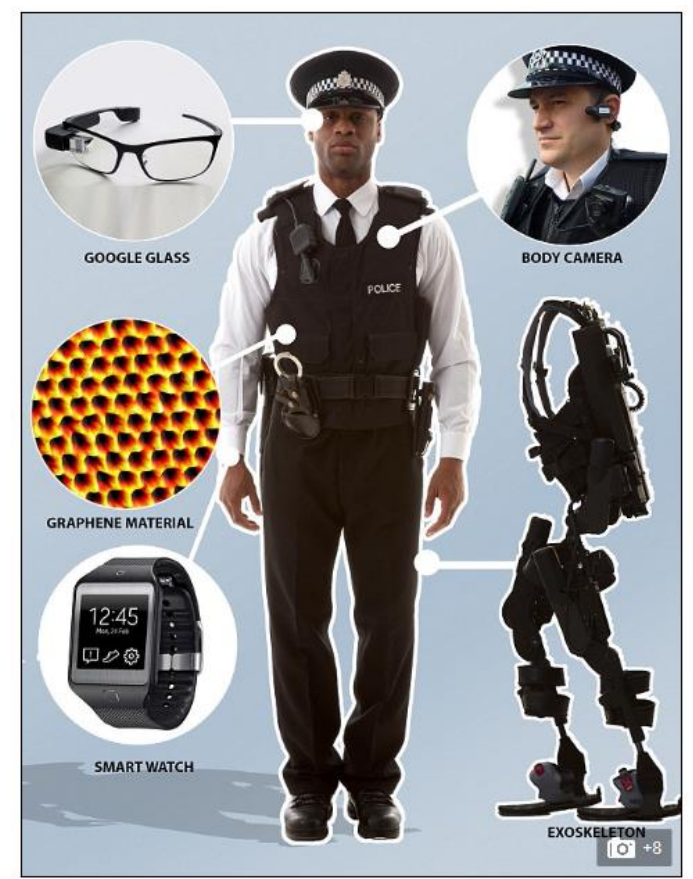

Photo source: http://www.dailymail.co.uk/news/article-2875775/Robocops-Google-Glass-wearable-computers-exoskeletons-police-forces-wishlists-officers.html 

PNNL RTA Monthly Report - December 2014

Other

\subsection{Other}

\subsubsection{Canatu: Nanobud®}

Technology name: Nanobuds

Description: Nanobud films are a "hybrid of Carbon Nanotubes and fullerenes" designed to conduct electricity while providing flexibility and durability fit for flexible and foldable devices. The flexible and transparent films can turn almost any surface into a touch-screen.

Status: Available

Funding:

Product link: http://www.canatu.com/nanobud/

Source: "Carbon 'nanobuds' could transform any surface into a touch screen or sensor." International Business Times. http://www.ibtimes.co.uk/carbon-nanobuds-could-transform-any-surface-into-touchscreen-sensor-1478515

\subsubsection{DuPont Microcircuit Materials}

Technology name: Stretchable electronic ink materials

Description: DuPont is producing "stretchable electronic ink materials" for use in wearables, including embedding comfortably and seamlessly into many standard fabrics. The stretchable inks are durable and washable (up to 100 wash cycles).

Status: Soon to be released - on display at recent industry events

\section{Funding:}

Product link: http://www.dupont.com/products-and-services/electronic-electrical-materials/printedelectronics/products/stetchable-inks-for-wearable-electronics.html

Source: "DuPont Intros Stretchable Inks for Wearable Electronics."PCB007. http://www.pcb007.com/pages/zone.cgi?a=105321

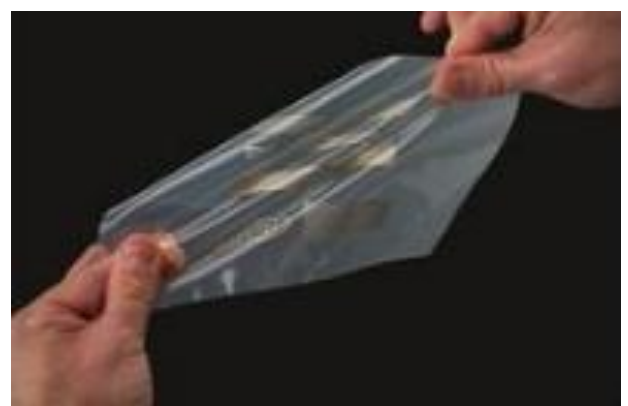

Photo source: http://www.dupont.com/products-and-services/electronic-electrical-materials/media/press-releases/20141204-stretchable-inks-for-wearableelectronics.html 


\subsubsection{Elliott Fight Dynamics: StrikeTec}

Technology name: StrikeTec sensor

Description: StrikeTec is a wrist-worn device that can track punch speed, force, type, count, and more to help an athlete analyze their punch performance. The data is communicated to the StrikeTec Boxing Training App via Bluetooth.

Status: Evolving

Funding: Crowdfunding

Product link: http://efdstriketec.com/

Source: StrikeTec Sensor Brings Wearable Technology to Boxing." Sport Techie. http://www.sporttechie.com/2014/12/15/striketec-sensor-brings-wearable-technology-to-boxing/

\subsubsection{Intel}

Technology name: Real-time facial recognition system

Description: Intel filed an application (No. 20140341430, "Method and Device for Detecting Face, and Non-Transitory Computer-Readable Recording Medium for Executing the Method") to patent real-time facial detection using an image or video from a mobile device. The system breaks up the image into regions and conducts face detection and face tracking operations. Partitioning the images is reported to reduce the time required by portable devices to detect faces in real time.

Status: Evolving

\section{Funding:}

Product link: http://www.freepatentsonline.com/y2014/0341430.html

Source: "Intel files patent for real-time facial recognition system." Biometric Update. http://www.biometricupdate.com/201412/intel-files-patent-for-real-time-facial-recognition-system

\subsubsection{Massachusetts Institute of Technology: Simultaneous Localization And Mapping}

Technology name: Simultaneous Localization And Mapping (SLAM) systems

Description: SLAM is designed to enable first responders to generate real-time maps. The system incorporates different positioning technologies including GPS to track physical location, LIDAR to measure light pulses, Gyroscopes to adjust for tilt, accelerometers to measure speed, barometer to measure air pressure changes, and a camera. The device was intended to provide first responders with "the ability to generate real-time maps as they explore a location, the remote transmission of the spatial layout of a building can help external commanders the ability to better manage emergency situations."

Status: Evolving 


\section{Funding:}

Product link: http://web.mit.edu/newsoffice/2012/automatic-building-mapping-0924.html

Source: "Portable Wearable Mapping System Powered by SLAM." Geoawesomeness. http://geoawesomeness.com/portable-wearable-mapping-system-powered-by-slam/

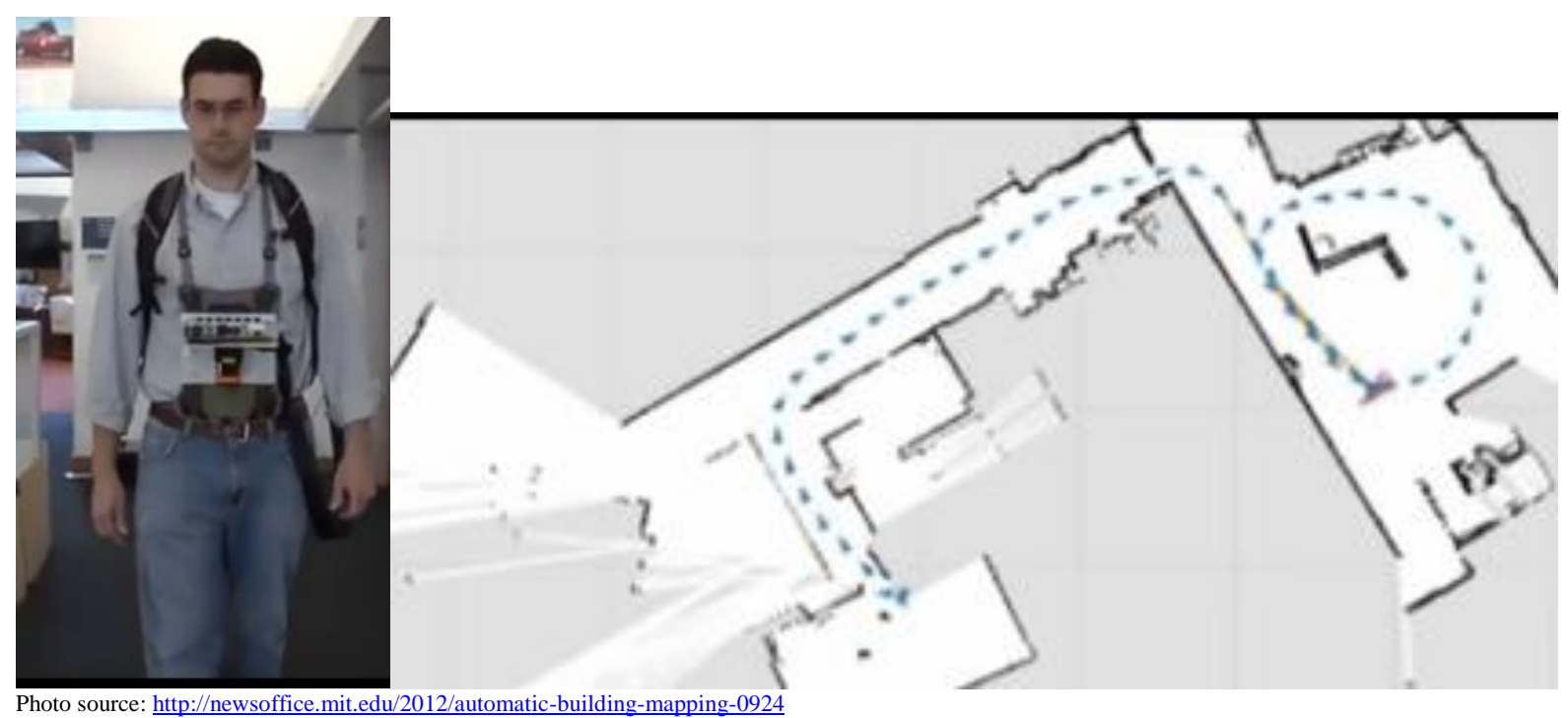

\subsubsection{Massachusetts Institute of Technology, Stratasys}

Technology name: 3D wearable skins

Description: Neri Oxman, director of the MIT Media Lab's Mediated Matter, and 3D printing company Stratasys are developing wearables "capable of keeping humans alive on other planets." The 3D "wearable skins" integrate engineered cells made by Stratasys's 3D printing technology and are designed to hold living matter while enabling a range of tasks from "producing and storing oxygen to absorbing nutrients and generating energy."

Status: Evolving

Funding:

Product link: http://neri.media.mit.edu/

Source: “An MIT Professor Is Creating 3D 'Wearable Skin' to Help You Survive Outer Space.” BostInno. http://bostinno.streetwise.co/2014/12/03/images-of-neri-oxmans-3d-wearable-skins-designed-for-outerspace/

\subsubsection{Norton, Betabrand}


Technology name: Radiofrequency identification (RFID)-blocking garments

Description: Norton and Betabrand have partnered to produce clothing that blocks unwanted wireless communications by blocking RFID and NFC transmissions. The machine-washable garments can shield credit cards from scanning devices while allowing cellular phone signals to pass through.

Status: Soon to be released - expected in February 2015

\section{Funding:}

Product link: http://www.betabrand.com/blog/33531/betabrand-norton-creates-worlds-first-rfidblocking-jeans-blazer

Source: "Norton-Approved Security Pockets Guard Against Security Theft." Wearable World News. http://wearableworldnews.com/2014/12/18/norton-approved-security-pockets-guard-security-theft/

\subsubsection{Performance Lab: ARDA Coaching Engine}

Technology name: ARDA Coaching Engine

Description: The ARDA Coaching Engine patented software platform that "creates an accurate picture of performance by blending and interpreting multiple data streams." The device fuses sports science, coaching, and technology to allow the user to interpret and analyze data regarding geography, physiology, and history (terrain, weather, speed, power, recent performance, sleep and measures of fatigue), essentially "building a 360-degree real-time view of user activity."

Status: Soon to be released - expected early 2015

\section{Funding:}

Product link: http://performancelab.co.nz/

Source: "Real-Time, Responsive, Actionable Advice: ARDA Coaching Engine; a Breakthrough in Wearable Fitness Software." BusinessWire. https://uk.finance.yahoo.com/news/real-time-responsiveactionable-advice-140000079.html

\subsubsection{Pinto}

Technology name: Pinto storage wristband

Description: Pinto is a wrist-worn storage device that connects wirelessly via Bluetooth to devices, no internet required. It provides 32-64GB of storage space, wireless charging, and password protection.

Status: Evolving

Funding: Crowdfunding

Product link: http://www.beanbeam.com/ 
Source: "Pinto Bluetooth storage wearable puts files on your wrist." Gizmag. http://www.gizmag.com/pinto-wireless-storage-wristband/35052/

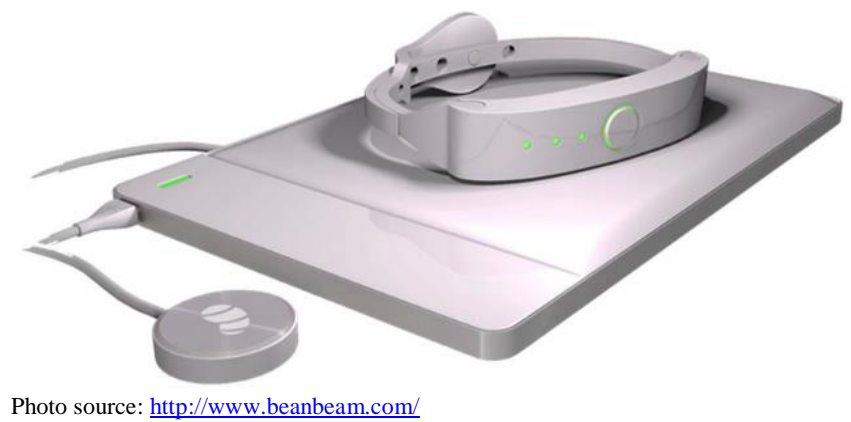

\subsubsection{Spansion, Sensoplex}

Technology name: Wearable development platform

Description: Spansion and Sensoplex announced their partnership to produce an evaluation and development kit platform allowing customers to develop wearable applications that "combine inertial, bio and environmental sensors, Bluetooth Low Energy (BLE), and ANT+[1] wireless protocols with ultra low-power processing." The platform comprises microcontrollers with low-power management, flash memory, interface for wireless data communications, and more.

Status: Evolving

\section{Funding:}

Product link: http://news.spansion.com/2014-12-16-Spansion-and-Sensoplex-Launch-HighPerformance-Low-Power-Wearable-Development-Platform

Source: "Spansion and Sensoplex Launch High-Performance, Low-Power Wearable Development Platform." Market Watch. http://www.marketwatch.com/story/spansion-and-sensoplex-launch-highperformance-low-power-wearable-development-platform-2014-12-16-718300

\subsubsection{Strap}

Technology name: Strap Metrics and Strap Kit

Description: The software development firm Strap has raised \$1 million seed investments that it will invest in product development. The company is the creator of Strap Metrics and Strap Kit analytics platforms designed for wearable applications. Strap Kit is a platform development framework for wearables, currently for Pebble and Wear and anticipated Apple Watch and Samsung Gear in the future. Strap Metrics (currently in beta) is designed to integrate with Pebble to tell a user "who is using your app, when and where."

\section{Status:}

Funding: \$1 million recently awarded in seed investments 
Product link: https://www.straphq.com/

Source: "Wearable tech startup Strap raises \$1.25M." Cincinatti. http://www.cincinnati.com/story/money/2014/12/02/cincytech-invests-local-startup/19765717/

\subsubsection{TUV Rheinland}

Technology name: Smart wearable device certification

Description: TUV Rheinland has launched the world's first certification standard for wearable devices. A seminar was held that welcomed manufacturers to discuss safety requirements, testing, quality, data accuracy and more, relative to the development of wearables. The standards address requirements in safety, wearability, and smart functionality, as well as wireless connectivity, electromagnetic compatibility, and hazardous substance use.

Status: Available

\section{Funding:}

Product link: http://www.tuv.com/media/china/press_1/EN.jpg

Source: "TUV Rheinland Visions for Quality Wearable Devices." http://www.tuv.com/news/en/greater_china/about_us_cn/press_3/pressreleases_gc_en/news_content_en_ 229120.html/wearables

\subsubsection{University of Toronto Mississauga}

Technology name: Player Tracking System

Description: The Player Tracking System app "tracks the location of players on a field and displays the data as a heat map." The system comprises a Moto360 watch worn by the player that communicates with an Onyx Beacon located on the field perimeter and ultimately uploaded to an IBM Bluemix server.

Status: Evolving

Funding: $\$ 7,500$ cash prize awarded at the SportsHack event sponsored by IBM and We Are Wearables

\section{Product link:}

Source: "UTM team wins wearable sports tech competition.” https://www.utm.utoronto.ca/mainnews/utm-team-wins-wearable-sports-tech-competition 


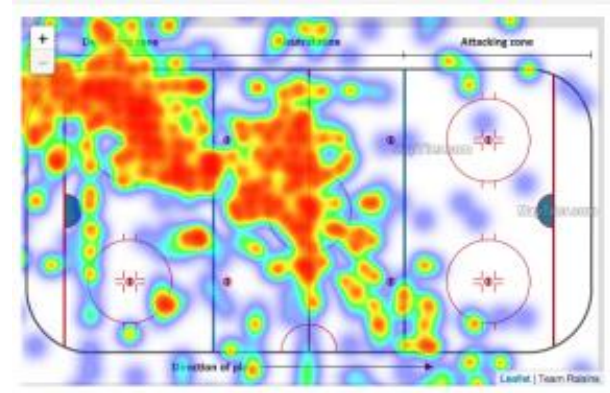

Photo source: https://www.utm.utoronto.ca/main-news/utm-team-wins-wearable-sports-tech-competition

\subsubsection{XOEye Technologies}

\section{Technology name:}

Description: XOEye Technologies announced its commitment of $\$ 1.5$ million in Series A funding in the wearables field. The 90-day funding round is co-led by Crestlight Ventures and Selous Venture Society. XOEye Technologies is a "leading enterprise wearables solutions company" that produces wearable technology for the industrial workplace, including operating systems for smart eyewear and other wearable platforms; hardware including ANSI-certified smartglasses with video, photo and two-way audio; and secure cloud-hosted software systems to manage wearable devices and interpret data.

Funding: $\$ 1.5$ million in Series A funding

Product link: http://www.xoeye.com/blog

Source: "XOEye Technologies Announces \$2 Million Series A Round to Fuel Hiring and Company Expansion in Enterprise Wearables Market." Market Wired. http://www.marketwired.com/pressrelease/xoeye-technologies-announces-2-million-series-a-round-fuel-hiring-company-expansion$\underline{1974706 . h t m}$

\subsubsection{YESJ EXPERT, AYEIM: AYEFI}

\section{Technology name: AYEFI}

Description: AYEFI is a GPS-equipped wearable designed for "safety, education, and entertainment." Users can use the device to notify others of their location. The device is also compatible with the user's smart phone.

Status: Soon to be available - expected February 2015

\section{Funding:}

Product link: http://www.ayefi.co/

Source: “AYEFI Launches Wearable, Smart-Safety Device.” PRNewswire.

http://www.prnewswire.com/news-releases/ayefi-launches-wearable-smart-safety-device-300008377.html 

PNNL RTA Monthly Report - October/November 2014 Appendix A: Technology Summary

\section{Appendix A}

\section{Technology Summary}


PNNL RTA Monthly Report - October/November 2014 Appendix A: Technology Summary

\section{Appendix A}

\section{Technology Summary}

The following spreadsheet provides a summary of the technologies compiled in this report. For an electronic copy, please contact Jaki Upton at jaki.upton@pnnl.gov. This information is not meant to be an exhaustive list nor an endorsement of any technology described herein. 


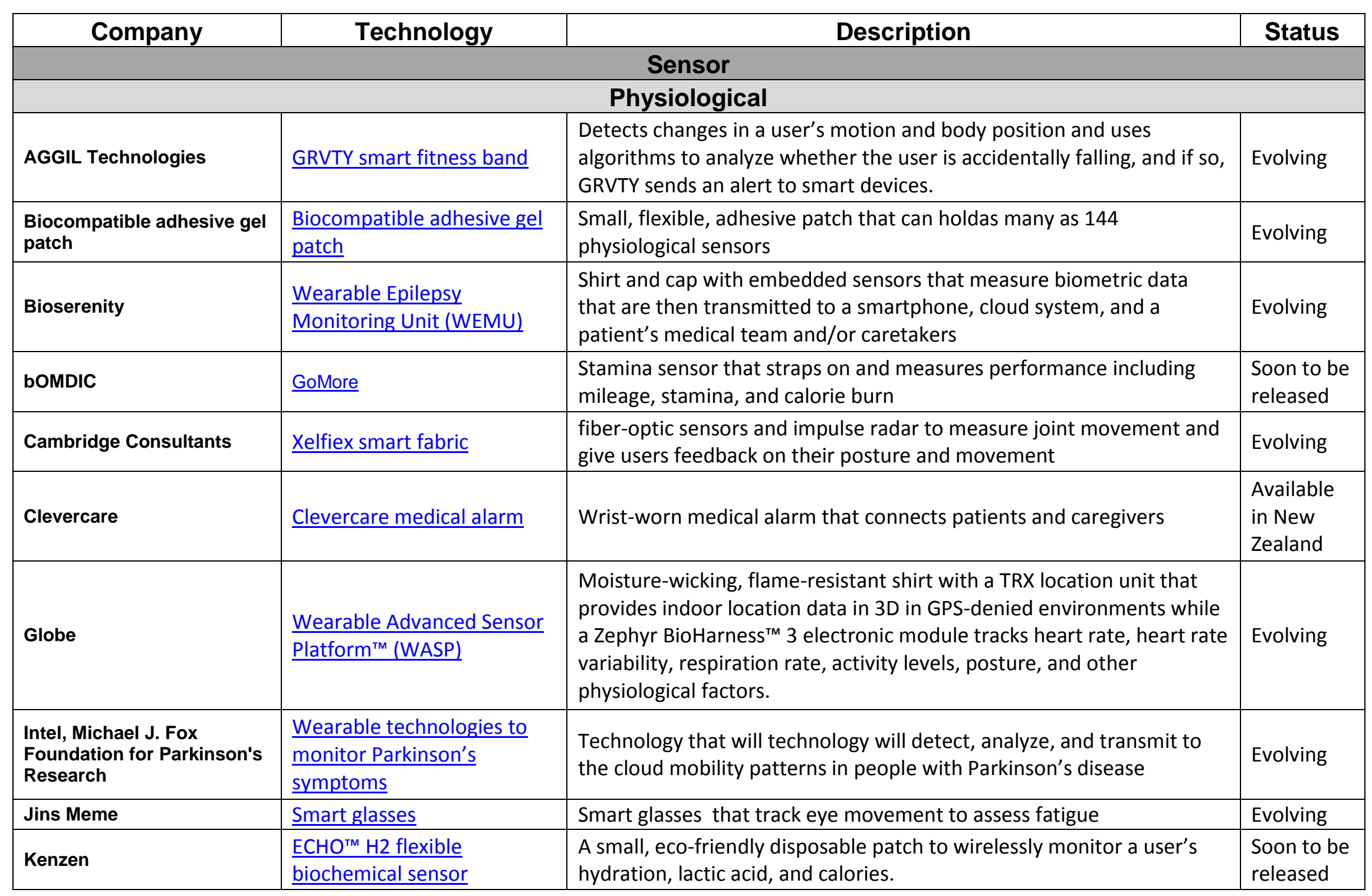


PNNL RTA Monthly Report - October/November 2014

Appendix A: Technology Summary

\begin{tabular}{|c|c|c|c|}
\hline $\begin{array}{l}\text { Li Cheng-Yuan, and You } \\
\text { Chuang-Wen, National } \\
\text { Taiwan University }\end{array}$ & NinjaFlex smart bandage & $\begin{array}{l}\text { 3-D-printer filament, bandage-like material paired with medical } \\
\text { sensors that monitor a patient's vital signs and transmit the data to a } \\
\text { patient's medical team using a smartphone or tablet. }\end{array}$ & Evolving \\
\hline LifeWatch, Vital Connect & $\begin{array}{l}\text { Vital Signs Patch cardiac } \\
\text { telemetry }\end{array}$ & $\begin{array}{l}\text { disposable, adhesive, remote cardiac monitoring chest-worn patch } \\
\text { that monitors ECG, Heart Rate, respiration rate, surface temperature, } \\
\text { and arterial blood oxygen saturation, and also acts as a wireless blood } \\
\text { pressure cuff }\end{array}$ & $\begin{array}{l}\text { Soon to be } \\
\text { released }\end{array}$ \\
\hline RipCurl & $\underline{\text { Search GPS smartwatch }}$ & $\begin{array}{l}\text { GPS-equipped, water-proof (to } 330 \text { feet) wristwatch monitors wave } \\
\text { counts and speeds, tracks 1,360 tide locations, and provides } \\
\text { notifications to the user }\end{array}$ & Available \\
\hline Seoul National University & Mechanical sensors & $\begin{array}{l}\text { Platinum film based on a spider's crack-shaped slit organs that detect } \\
\text { minute vibrations. }\end{array}$ & Evolving \\
\hline Spire & $\underline{\text { Spire sensor clip }}$ & $\begin{array}{l}\text { Clips onto a user's garments and tracks breathing patterns to measure } \\
\text { and notify a user of his/her focus, tension, calm, and activity. }\end{array}$ & Available \\
\hline $\begin{array}{l}\text { U.S. Air Force Research } \\
\text { Laboratory, University of } \\
\text { Massachusetts Amherst, } \\
\text { GE }\end{array}$ & $\begin{array}{l}\text { Patch to measure } \\
\text { biomarkers in sweat }\end{array}$ & $\begin{array}{l}\text { Wearable sensor patch that monitors chemicals in the user's sweat to } \\
\text { indicate stress and fatigue }\end{array}$ & Evolving \\
\hline U-Wake & $\underline{\text { U-Wake sensor }}$ & $\begin{array}{l}\text { headband uses EEG sensors to monitor brainwaves and analyze } \\
\text { fatigue level }\end{array}$ & Evolving \\
\hline VivaLnk & $\underline{\text { eSkin }^{\mathrm{TM}} \text { Thermometer }}$ & $\begin{array}{l}\text { electronic circuitry with embedded sensors on a thin, flexible material } \\
\text { that comfortably adhere to the skin to measure temperature }\end{array}$ & Evolving \\
\hline WiseWear & Evolve ${ }^{\mathrm{TM}}$ & $\begin{array}{l}\text { Uses the Nomad core sensor platform in a chest strap, shirt clip, or } \\
\text { wristband to track heart rate, respiration, motion, global movement, } \\
\text { galvanic skin response, and blood oxygenation and transmitted to a } \\
\text { mobile device. }\end{array}$ & $\begin{array}{l}\text { Soon to be } \\
\text { released }\end{array}$ \\
\hline \multicolumn{4}{|c|}{ Chemical/Particulate } \\
\hline Breathe & Breathe & $\begin{array}{l}\text { Air quality sensors in a wearable clip to measure air pollution, report a } \\
\text { user's air pollution readings to crowdsourced dataset, and alert a user } \\
\text { of air pollution. }\end{array}$ & Evolving \\
\hline
\end{tabular}


PNNL RTA Monthly Report - October/November 2014

Appendix A: Technology Summary

\begin{tabular}{|c|c|c|c|}
\hline Wepo & Wepo air pollution monitor & $\begin{array}{l}\text { wearable pollution-exposure-monitoring device equipped with an } \\
\text { electrochemical carbon monoxide sensor }\end{array}$ & $\begin{array}{l}\text { Soon to be } \\
\text { released }\end{array}$ \\
\hline \multicolumn{4}{|c|}{ Other } \\
\hline First Sign, MaceWear & $\begin{array}{l}\text { 5-in-1 Pod automatic } \\
\text { personal security system }\end{array}$ & $\begin{array}{l}\text { Attaches to common devices such as a keychain, belt clip, wristband, } \\
\text { pendant or headband, and serves as an assault alert, fall alert, and } \\
\text { panic button. }\end{array}$ & Available \\
\hline $\begin{array}{l}\text { Pauline van Dongen and TU } \\
\text { Eindhoven \& Textile } \\
\text { Museum }\end{array}$ & $\begin{array}{l}\text { Vigour clothing for } \\
\text { rehabilitation and physical } \\
\text { therapy }\end{array}$ & $\begin{array}{l}\text { Clothing that tracks a user's movements and make the data available } \\
\text { to a mobile app for use by the patient, therapist, caretakers, etc., with } \\
\text { intended applications in rehabilitation and physical therapy }\end{array}$ & Evolving \\
\hline ReTiSense & $\underline{\text { Stridalyzer smart insoles }}$ & $\begin{array}{l}\text { uses insoles equipped with patent-pending technology of multiple } \\
\text { sensors that communicate stride information to a smart device }\end{array}$ & $\begin{array}{l}\text { Soon to be } \\
\text { released }\end{array}$ \\
\hline Torch & $\underline{\text { Torch }}$ & $\begin{array}{l}\text { Uses infrared sensors worn on the head or chest that emit an audible } \\
\text { or vibrating warning when the user approaches an obstacle. }\end{array}$ & Evolving \\
\hline Triax SIM-P & $\underline{\text { Triax SIM-P head band }}$ & $\begin{array}{l}\text { Triax SIM-P fits into a headband or cap and measures G-force of head } \\
\text { impacts and sends alerts to smart devices. }\end{array}$ & Available \\
\hline Microsoft & $\underline{\text { Virtual reality headset }}$ & $\begin{array}{l}\text { Microsoft is anticipated to unveil a virtual reality headset at the E3 } \\
\text { conference in June } 2015 .\end{array}$ & Evolving \\
\hline Oculus & $\underline{\text { Oculus }}$ & $\begin{array}{l}\text { Oculus announced three acquisitions/partnerships: Nimble VR, 13th } \\
\text { Lab, and Chris Bregler, motion expert }\end{array}$ & \\
\hline Osterhout Design Group & $\underline{\text { Smart glass platform }}$ & $\begin{array}{l}\text { Smart-glass platform capable of running full Android tablet software } \\
\text { and sharp optics on clear glasses }\end{array}$ & $\begin{array}{l}\text { Soon to be } \\
\text { released }\end{array}$ \\
\hline Sony & Single-Lens Display Module & Attaches and beams display onto user's glasses & Evolving \\
\hline \multicolumn{4}{|c|}{ Body-worn } \\
\hline Google, Intel & Google Glass v2 & Intel being integrated into the upcoming iteration of Google Glass & Evolving \\
\hline Honeywell & $\begin{array}{l}\text { Wearable Solution for the } \\
\text { Dolphin 70e Mobile } \\
\text { Computer }\end{array}$ & $\begin{array}{l}\text { Hands-free, wrist-worn Dolphin 70e Black mobile device intended to } \\
\text { support warehouse operations }\end{array}$ & $\begin{array}{l}\text { Soon to be } \\
\text { released }\end{array}$ \\
\hline
\end{tabular}


PNNL RTA Monthly Report - October/November 2014

Appendix A: Technology Summary

\begin{tabular}{|c|c|c|c|}
\hline \multicolumn{4}{|c|}{ Power } \\
\hline \multicolumn{4}{|c|}{ Chargers } \\
\hline SolarHug & $\underline{\text { SolarHug bracelet }}$ & $\begin{array}{l}\text { Transforms solar energy into power for a smartphone or other devices } \\
\text { via USB. }\end{array}$ & Evolving \\
\hline \multicolumn{4}{|c|}{ Self-Powering/Harvesting } \\
\hline $\begin{array}{l}\text { Lanzhou University, } \\
\text { Chinese Academy of } \\
\text { Sciences }\end{array}$ & $\begin{array}{l}\text { Wearable triboelectric } \\
\text { generator }\end{array}$ & Wearable triboelectric generators that harvest body motion energy & Evolving \\
\hline Texas Instruments & $\underline{\text { Wireless sensor technology }}$ & $\begin{array}{l}\text { Electronics that turn small amounts of power generated by harvested } \\
\text { sources (body movement) into useful power sources }\end{array}$ & Evolving \\
\hline \multicolumn{4}{|c|}{ Power Supplies } \\
\hline Fujitsu Laboratories Ltd. & Middleware & $\begin{array}{l}\text { Sensing middleware that simplifies development of low-power sensing } \\
\text { applications by essentially intercepting requests for notification from } \\
\text { applications }\end{array}$ & Evolving \\
\hline Telepathy Inc. & Jumper & $\begin{array}{l}\text { A neck-worn and eye-worn device with an optical display, camera, } \\
\text { microphone, and sensors and an app that allow the user to share their } \\
\text { field of vision and other information with others. }\end{array}$ & $\begin{array}{l}\text { Soon to be } \\
\text { released }\end{array}$ \\
\hline \multicolumn{4}{|c|}{ Short-range low-power Bluetooth } \\
\hline Alpha & NFC ring & $\begin{array}{l}\text { Communicates with other NFC devices, allowing the user to unlock } \\
\text { NFC-enabled doors, communicate with NFC-enabled phones, and } \\
\text { transfer information. }\end{array}$ & Available \\
\hline Caseco & $\begin{array}{l}\text { Blu-Toque dual-layered } \\
\text { Bluetooth hat }\end{array}$ & $\begin{array}{l}\text { Hat equipped with Bluetooth technology that allows the user to take } \\
\text { calls, listen to music, etc. wirelessly and without headphones. }\end{array}$ & Available \\
\hline \multicolumn{4}{|c|}{ Hands-free Operations } \\
\hline Fin & Fin thumb ring & $\begin{array}{l}\text { Smart thumb ring that utilizes Bluetooth and allows the user to engage } \\
\text { with smart devices and appliances to share information and } \\
\text { communicate. }\end{array}$ & \\
\hline
\end{tabular}


PNNL RTA Monthly Report - October/November 2014 Appendix A: Technology Summary

\begin{tabular}{|c|c|c|c|}
\hline Fullpower & $\begin{array}{l}\text { MotionX Sensor-Fusion } \\
\text { technology }\end{array}$ & $\begin{array}{l}\text { Awarded a patent }(8,902,154) \text { for motion and gesture control in } \\
\text { wearable devices, supplementing the company's MotionX Sensor- } \\
\text { Fusion technology. }\end{array}$ & Available \\
\hline $\begin{array}{l}\text { Institute for Integrative } \\
\text { Nanosciences, Institute for } \\
\text { Solid State and Materials } \\
\text { Research Dresden }\end{array}$ & $\begin{array}{l}\text { Flexible magnetic field } \\
\underline{\text { sensors }}\end{array}$ & $\begin{array}{l}\text { Flexible bismuth Hall sensors that can bend around the wrist or be } \\
\text { positioned on the finger, with only a minor reduction in sensor } \\
\text { performance, and create an interactive pointing device for wearable } \\
\text { devices. }\end{array}$ & Evolving \\
\hline \multicolumn{4}{|c|}{ Exoskeletons } \\
\hline $\begin{array}{l}\text { Daewoo Shipbuilding and } \\
\text { Marine Engineering }\end{array}$ & Robotic suit & $\begin{array}{l}\text { An exoskeleton suits of light-weight aluminum alloy and steel, with } \\
\text { straps at the feet, thigh, waist, and chest, and comprising hydraulic } \\
\text { joints and electric motors connected to a backpack that powers the } \\
\text { robotic suit }\end{array}$ & Evolving \\
\hline $\begin{array}{l}\text { Defense Advanced } \\
\text { Research Projects Agency }\end{array}$ & Airlegs & $\begin{array}{l}\text { Powered by a tank of compressed air, pulleys and electronic sensors } \\
\text { connect to braces that essentially help pull the user's legs }\end{array}$ & Evolving \\
\hline \multicolumn{4}{|c|}{ Other } \\
\hline Canatu & Nanobud & $\begin{array}{l}\text { designed to conduct electricity while providing flexibility and durability } \\
\text { fit for flexible and foldable devices }\end{array}$ & Available \\
\hline $\begin{array}{l}\text { DuPont Microcircuit } \\
\text { Materials }\end{array}$ & $\begin{array}{l}\text { Stretchable electronic ink } \\
\text { materials }\end{array}$ & $\begin{array}{l}\text { Durable, stretchable electronic ink materials that can be embedded } \\
\text { into garments }\end{array}$ & $\begin{array}{l}\text { Soon to be } \\
\text { released }\end{array}$ \\
\hline Elliott Fight Dynamics & $\underline{\text { StrikeTec sensor }}$ & $\begin{array}{l}\text { Wrist-worn device that can track punch speed, force, type, count, and } \\
\text { more to help an athlete analyze their punch performance }\end{array}$ & Evolving \\
\hline Intel & $\begin{array}{l}\text { Real-time facial recognition } \\
\text { system }\end{array}$ & $\begin{array}{l}\text { Intel patented a system for real-time facial detection using an image or } \\
\text { video from a mobile device. }\end{array}$ & Evolving \\
\hline
\end{tabular}


PNNL RTA Monthly Report - October/November 2014

Appendix A: Technology Summary

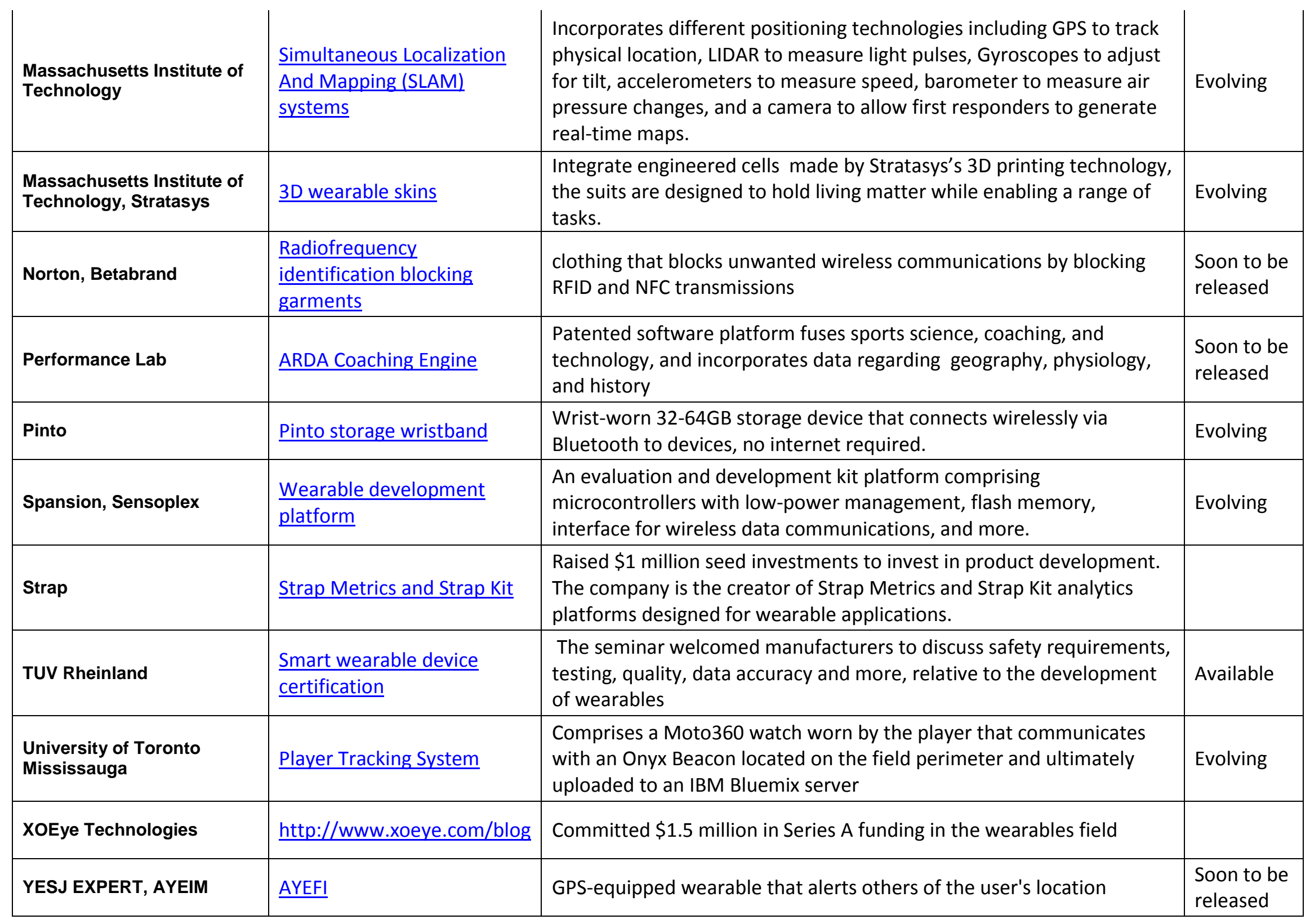


PNNL RTA Monthly Report - October/November 2014

Appendix A: Technology Summary

\begin{tabular}{|c|c|c|c|}
\hline \multicolumn{4}{|c|}{ General } \\
\hline CBInsights & $\begin{array}{l}\text { Top } 10 \text { Wearable Tech Deals } \\
\text { in } 2014\end{array}$ & $\begin{array}{l}\text { This article summarizes the top } 10 \text { financing deals (totaling nearly \$1 } \\
\text { billion in funding) in wearables in } 2014 \text {. }\end{array}$ & \\
\hline Intel & $\underline{\text { Intel partnerships }}$ & $\begin{array}{l}\text { Intel partnered with eyewear maker Luxottica Group to create smart } \\
\text { eyewear; Google for the next generation of Google Glass; SMS Audio } \\
\text { to create the BioSport headphones; and Opening Ceremony to create } \\
\text { a smart bracelet. }\end{array}$ & \\
\hline $\begin{array}{l}\text { Intelligence Advanced } \\
\text { Research Projects Activity }\end{array}$ & $\begin{array}{l}\text { Request for Information for } \\
\underline{\text { wearables }}\end{array}$ & $\begin{array}{l}\text { The Intelligence Advanced Research Projects Activity issued a request } \\
\text { for information for “Future Applications of Sensing Technologies for } \\
\text { Fidelitous Wearable Devices. }\end{array}$ & Evolving \\
\hline UK Home Office & $\underline{\text { UK Police Forces technology }}$ & $\begin{array}{l}\text { The UK Home Office is exploring opportunities to outfit British police } \\
\text { officers with protective wearables }\end{array}$ & \\
\hline Wareable & $\begin{array}{l}\text { Mergers and acquisitions of } \\
\underline{2014}\end{array}$ & $\begin{array}{l}\text { This article summarizes the top mergers and acquisitions of } 2014 \\
\text { relative to wearables: Facebook and Oculus VR, Intel and Basis Science, } \\
\text { Facebook and Moves, Google and Nest, Microsoft and Osterhout } \\
\text { Design Group, and Covidien and Zephyr. }\end{array}$ & \\
\hline Yahoo! Inc. & Yahoo Inc. wearables & Yahoo announced it will be growing in the wearable devices industry. & \\
\hline
\end{tabular}




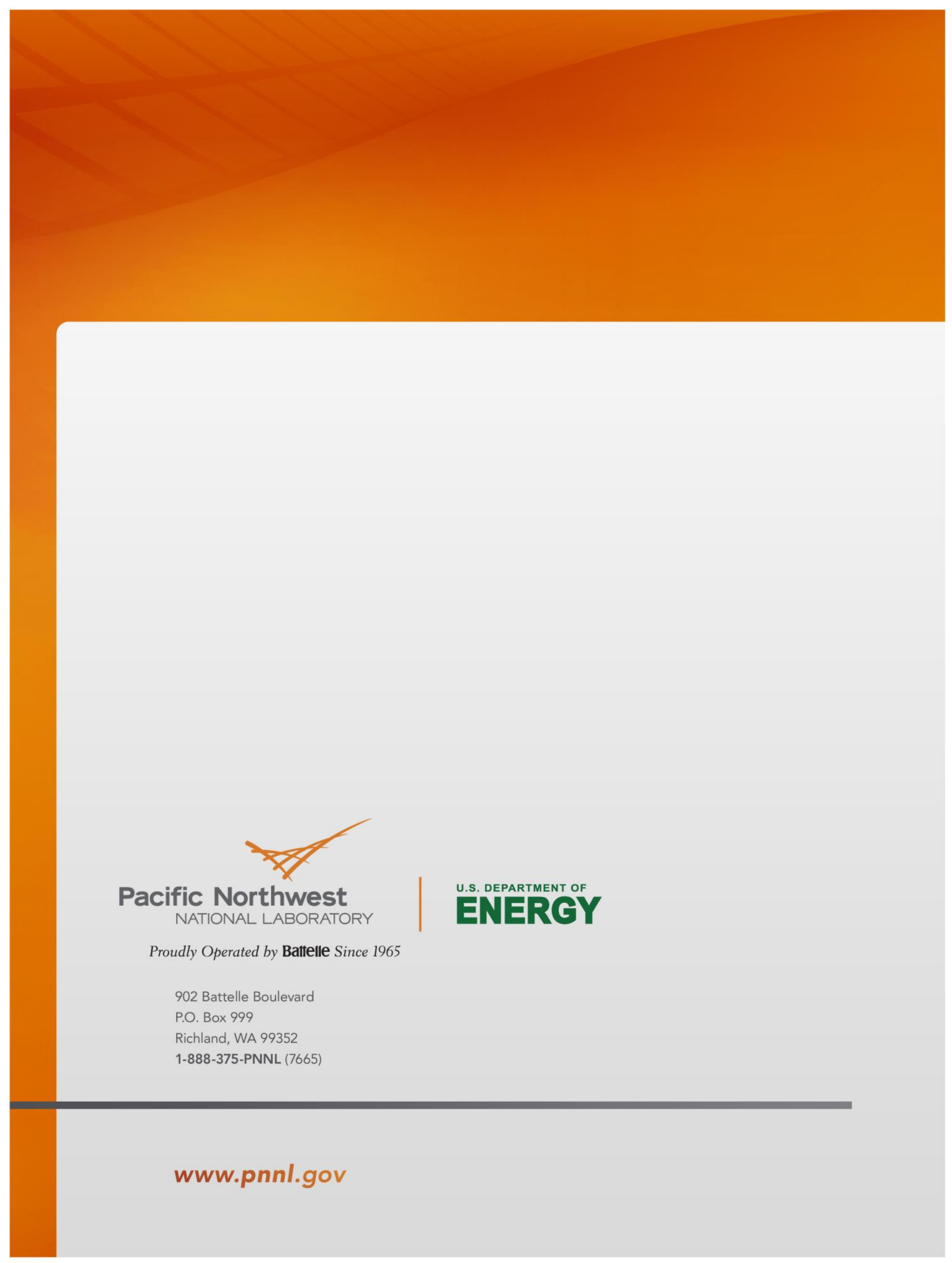

